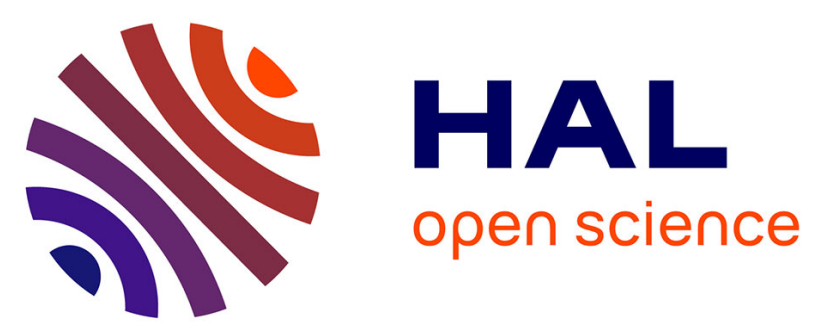

\title{
Nuclear Magnetic Resonance Spectroscopy: A Multifaceted Toolbox to Probe Structure, Dynamics, Interactions, and Real-Time In Situ Release Kinetics in Peptide-Liposome Formulations
}

Camille Doyen, Eric Larquet, Pierre-Damien Coureux, Oriane Frances, Frédéric Herman, Serge Sablé, Jean-Pierre Burnouf, Christina Sizun, Ewen Lescop

\section{- To cite this version:}

Camille Doyen, Eric Larquet, Pierre-Damien Coureux, Oriane Frances, Frédéric Herman, et al.. Nuclear Magnetic Resonance Spectroscopy: A Multifaceted Toolbox to Probe Structure, Dynamics, Interactions, and Real-Time In Situ Release Kinetics in Peptide-Liposome Formulations. Molecular Pharmaceutics, 2021, 18 (7), pp.2521-2539. 10.1021/acs.molpharmaceut.1c00037 . hal-03301899

\author{
HAL Id: hal-03301899 \\ https://hal.science/hal-03301899
}

Submitted on 27 Jul 2021

HAL is a multi-disciplinary open access archive for the deposit and dissemination of scientific research documents, whether they are published or not. The documents may come from teaching and research institutions in France or abroad, or from public or private research centers.
L'archive ouverte pluridisciplinaire $\mathbf{H A L}$, est destinée au dépôt et à la diffusion de documents scientifiques de niveau recherche, publiés ou non, émanant des établissements d'enseignement et de recherche français ou étrangers, des laboratoires publics ou privés. 


\title{
Nuclear Magnetic Resonance Spectroscopy: A Multifaceted Toolbox to Probe Structure, Dynamics, Interactions, and Real-Time In Situ Release Kinetics in Peptide-Liposome Formulations
}

Camille Doyen, Eric Larquet, Pierre-Damien Coureux, Oriane Frances, Frédéric Herman, Serge Sablé, Jean-Pierre Burnouf, Christina Sizun,* and Ewen Lescop*

Cite This: https://doi.org/10.1021/acs.molpharmaceut.1c00037

Read Online

ACCESS | Lلll Metrics \& More | 国 Article Recommendations | s supporting Information

\begin{abstract}
Liposomal formulations represent attractive biocompatible and tunable drug delivery systems for peptide drugs. Among the tools to analyze their physicochemical properties, nuclear magnetic resonance (NMR) spectroscopy, despite being an obligatory technique to characterize molecular structure and dynamics in chemistry as well as in structural biology, yet appears to be rather sparsely used to study drug-liposome formulations. In

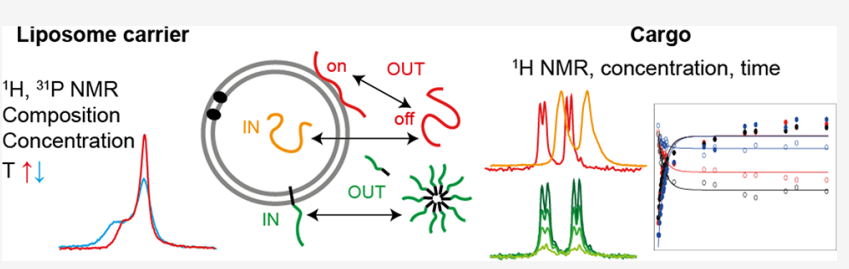
this work, we exploited several facets of liquid-state NMR spectroscopy to characterize liposomal delivery systems for the apelinderived K14P peptide and K14P modified by $\mathrm{N} \alpha$-fatty acylation. Various liposome compositions and preparation modes were analyzed. Using NMR, in combination with cryo-electron microscopy and dynamic light scattering, we determined structural, dynamic, and self-association properties of these peptides in solution and probed their interactions with liposomes. Using ${ }^{31} \mathrm{P}$ and ${ }^{1} \mathrm{H}$ NMR, we characterized membrane fluidity and thermotropic phase transitions in empty and loaded liposomes. Based on diffusion and ${ }^{1} \mathrm{H}$ NMR experiments, we localized and quantified peptides with respect to the interior/exterior of liposomes and changes over time and upon thermal treatments. Finally, we assessed the release kinetics of several solutes and compared various formulations. Taken together, this work shows that NMR has the potential to assist the design of peptide/liposome systems and more generally drug delivery systems.
\end{abstract}

KEYWORDS: peptide, liposomes, NMR spectroscopy, cargo release, phospholipids, dynamics, interaction

\section{INTRODUCTION}

In the pharmaceutical industry, therapeutic peptides have emerged as an important class of compounds of intermediate size between small molecules and protein-based biologics. ${ }^{1,2}$ In 2018, more than 60 therapeutic peptides were approved, and $\sim 150$ were under active clinical development. ${ }^{2}$ Peptides often show good tolerability and are endowed with high efficacy and specific activity, as illustrated by agonists and antagonists of Gprotein-coupled receptors. However, they generally suffer from poor chemical and physical stability, short plasma half-life, and poor oral bioavailability. Slow diffusion of peptides across membranes, linked to their size, 3D structure, and/or hydrophilicity-hydrophobicity balance, hampers drug delivery. Peptide pharmacokinetic properties have been improved by chemical optimization, e.g., by cyclization, $N$-methylation, or bioconjugation to PEG, lipids, or proteins. These strategies allow reducing doses or administration frequency and hence reducing adverse side effects such as toxicity and immunogenicity.

Drug carrier and drug delivery systems (DDS), such as liposomes, micro- and nanoparticles, facilitate sustained drug release. $^{3-5}$ DDSs are also used to improve the solubility, stability, biodistribution, and targeting of bioactive com- pounds. Liposomes form a DDS class that has been widely studied. ${ }^{6,7}$ Owing to their biocompatibility, good safety profile, and protective effect toward their cargo, their potential as DDSs for small compounds has been recognized early on. ${ }^{6,7}$ Liposomes have also been used as DDSs for peptides and proteins, e.g., for insulin or vasoactive intestinal peptides. ${ }^{5-7}$ They paved the way to nanomedicine. ${ }^{8}$ Liposomes consist of $50 \mathrm{~nm}$ to $5 \mu \mathrm{m}$-sized vesicles formed by single or multiple phospholipid bilayers, which define an inner aqueous compartment isolated from the surrounding environment. Depending on their physicochemical properties, and in particular on their partition coefficient, drugs are either encapsulated within the hydrophobic bilayers or physically entrapped in the inner compartment or may partition between both environments. Fine-tuning of the composition, size, and lamellarity of

Received: January 17, 2021

Revised: April 14, 2021

Accepted: April 14, 2021 
liposomes allows controlled release and precise targeting of the encapsulated active ingredients.

Optimizing liposome structure and drug release properties requires advanced analytical and structural techniques. ${ }^{9-11}$ Nuclear magnetic resonance (NMR) spectroscopy is a powerful tool to probe the structure and dynamics of virtually all types of molecules at atomic resolution, in liquid and condensed states. Solid-state NMR (ssNMR) is wellrecognized for characterizing lipid systems and deciphering the mode of action of membrane-active peptides. ${ }^{12-15}$ ssNMR has been utilized to investigate nanoparticle- as well as lipidbased drug delivery systems. ${ }^{16-19}$ Recently, the potential of both ssNMR and liquid-state NMR was illustrated for drug delivery applications to biologics. ${ }^{20}$ Surprisingly, the number of liquid-state NMR studies carried out on drug-loaded liposomes, and more generally on drug delivery systems, is still limited. ${ }^{21-31}$ We therefore aimed in this study to illustrate the versatility of liquid-state NMR spectroscopy to characterize various facets of liposome-peptide formulation: liposome and peptide structures, their mutual interactions, stability of the formulation, and peptide release properties upon heating. We carried out this work on a series of apelin-derived peptides encapsulated into liposomes of various compositions.

Our model is the K14P peptide, derived from the endogenous apelin ligands of the G-protein-coupled receptor APJ, which compose the apelinergic system. ${ }^{32} \mathrm{~K} 14 \mathrm{P}$ (apelin residues 61-74) itself was shown to bind to APJ in $\mathrm{CHO}$ cells. ${ }^{33}$ Regulation by the apelinergic system is associated to various physiological and pathological processes involved in cardiovascular functions, body fluid homeostasis, and in the gastrointestinal and immune systems. ${ }^{34}$ Several exogenous apelin isoforms have entered clinical trials, to test beneficial action in type 2 diabetes and cardio-protection due to inotropic and hemodynamic effects. ${ }^{35,36}$ However, apelins suffer from short circulating lifetimes. ${ }^{37}$ [Pyr]-apelin-13, the main apelin isoform in the human heart, ${ }^{38}$ has a half-life of $<15$ min in physiological fluids, and variants containing unnatural amino acids have a half-life of $<1 \mathrm{~h}^{39}$ Encapsulation of [Pyr]apelin-13 in pegylated liposomal nanocarriers resulted in significantly extended lifetime in vitro and in vivo, with up to 6 days in plasma with sustained activity. ${ }^{35}$ Pegylation of apelin36 resulted in prolonged availability in blood plasma. ${ }^{40}$ When incorporated in liposomes, pegylated apelin-13 could be efficiently delivered to endothelial cells in tumors, showing the potential of liposomes as a DDS to prolong apelin-like activity. ${ }^{41}$ The interaction mode of apelin-derived peptides with liposomes is still largely unknown, although NMR has been used previously to get detailed insight into the structure of apelin peptides, their molecular interactions with membrane models, and the self-aggregation properties of their various derivatives. $^{42-45}$

Here, we combined different facets of liquid-state NMR spectroscopy to get a comprehensive view of the structural and dynamic properties of the apelin-derived peptide K14P and several $\mathrm{N} \alpha$-fatty acylated variants as well as of the phospholipid bilayers in liposomal formulations. We focused on classical and robust ${ }^{1} \mathrm{H}$ (1D, 2D TOCSY/NOESY, DOSY)-, ${ }^{19} \mathrm{~F}$-, and ${ }^{31} \mathrm{P}$ based experiments that are readily accessible to most of the NMR laboratories without an extensive setup. We show how to analyze the data to describe the structure and the dynamics of the peptides and liposomes as well as their mutual interactions, in combination with the more conventionally used dynamic light scattering (DLS) and cryo-electron microscopy (cryo-
EM) techniques. We also demonstrate that heat-induced peptide release can be monitored in real time and in situ by simple $1 \mathrm{D}{ }^{1} \mathrm{H}$ and DOSY NMR experiments. These tools should be easily transposed to applications ranging from quality control and in vitro stability assessment before administration to modeling of release in vitro for liposome/ peptide formulation but also for other cargos or other DDSs.

\section{MATERIALS AND METHODS}

2.1. Materials. Fluorenylmethyloxycarbonyl (Fmoc)-protected amino acids and $\mathrm{O}$-( $1 \mathrm{H}$-6-chlorobenzotriazole-1-yl)1,1,3,3-tetramethylaminium hexafluorophosphate (HCTU) were purchased from Protein Technologies. Chlorotrityl resin (H-L-Pro-2CTC) was purchased from Iris Biotech. 1,2Dipalmitoyl-sn-glycero-3-phosphocholine (DPPC) and a 1,2dimyristoyl-sn-glycero-3-phospho-(1'-rac-glycerol) sodium salt (DMPG) were purchased from Avanti Polar Lipids. Cholesterol (CHOL), hexadecanoyl (palmitic, C16) chloride, fluorinated undecanoyl $\left(\mathrm{CF}_{3}-\left(\mathrm{CF}_{2}\right)_{7}-\left(\mathrm{CH}_{2}\right)_{2}-\mathrm{CO}-, \mathrm{C} 11 \mathrm{~F}\right)$ chloride, and $\mathrm{N}, \mathrm{N}$-diisopropylethylamine (DIEA) were purchased from Sigma-Aldrich. Undecanoyl (C11) chloride was purchased from ABCR. Dimethylformamide (DMF) and piperidine were from Carlo Erba, and triisopropylsilane (TIS) and trifluoroacetic acid (TFA) were from Alfa Aesar.

2.2. Peptide Preparation. The K14P peptide (apelin residues 61-74, KFRRQRPRLSHKGP) was prepared by solid-phase peptide synthesis on a Tribute UV-IR synthesizer (Gyros Protein Technologies) using Fmoc chemistry. Coupling was performed in DMF using 3 equiv of protected amino acids relative to resin ( $0.5 \mathrm{mmol}$ scale, $0.16 \mathrm{mmol} \mathrm{g}^{-1}$ loading), activated by 3 equiv of the HCTU coupling agent in the presence of 5 equiv of DIEA. Protecting groups were removed with $20 \%$ piperidine in DMF. After addition of the final amino acid, the peptide was either cleaved from the resin or conjugated to a fatty acid.

For nonacylated K14P, the final deprotection step and peptide cleavage from the resin were done in a mixture of TFA, $\mathrm{H}_{2} \mathrm{O}$, phenol, and TIS in an 88/5/5/2 v/v/v/v ratio for 4-5 h. The peptide was then precipitated and washed several times with ice-cold diethyl ether and lyophilized prior to purification.

For fatty acylated K14P, after removal of the Fmoc protective group at the peptide $\mathrm{N}$-terminus, the samples on the resin $(0.32 \mathrm{mmol}$ scale $)$ were incubated with 2 equiv of fatty acyl $(\mathrm{C} 16, \mathrm{C} 11$, or $\mathrm{C} 11 \mathrm{~F})$ chloride and 3.5 equiv of DIEA in dichloromethane under shaking for at least $1 \mathrm{~h}$. The samples were then washed several times with dichloromethane, and cleavage was carried out with the same protocol as for nonacylated K14P.

Peptide purification was carried out by reversed-phase highperformance liquid chromatography (HPLC) on a Gilson GX271 liquid handler using a CSH C18 column (Waters, $50 \times$ $250 \mathrm{~mm}$; granulometry, $5 \mu \mathrm{m}$ ). The mobile phase contained water and acetonitrile. TFA counterions were subsequently exchanged with acetate using a strong anion exchange resin (AG 1-X4 resin, hydroxide form, 100-200 mesh, Bio-Rad) treated successively with 1.6 and $0.16 \mathrm{M}$ acetic acid. The identity and purity of the products were confirmed by mass spectrometry and NMR.

2.3. Liposome Preparation. DPPC/DMPG/cholesterol liposomes were prepared by weighing DPPC (molecular weight, $\left.M_{\mathrm{W}}, 734.04 \mathrm{~g} \mathrm{~mol}^{-1}\right)$, DMPG $\left(M_{\mathrm{W}}, 688.85 \mathrm{~g} \mathrm{~mol}^{-1}\right)$, and cholesterol $\left(M_{\mathrm{W}}, 386.65\right.$ g.mol $\left.{ }^{-1}\right)$ in an $82.8 / 5.4 / 11.8$ mass ratio. ${ }^{46}$ DPPC/DMPG liposomes without cholesterol 
were prepared with the same DPPC/DMPG mass ratio, i.e., 93.9:6.1. The powders were dissolved in a dichloromethane/ ethanol $50 / 50 \mathrm{v} / \mathrm{v}$ mixture ( $1 \mathrm{~mL}$ final volume). The solution was then dried under a nitrogen stream to obtain a thin film. Solvent evaporation was completed by placing the sample under vacuum for $3 \mathrm{~h}$. The film was hydrated with $80 \mathrm{mM}$ HEPES pH 7.4 and $100 \mathrm{mM} \mathrm{NaCl}$ buffer. The buffer volume was calculated to obtain a concentration of $60 \mathrm{mg} \mathrm{mL}^{-1}$ phospholipids and cholesterol. Small liposomal vesicles were prepared by following two different protocols. In the first protocol, the lipid suspension was sonicated twice for $2 \mathrm{~min}$. In the second protocol, the sample was extruded 15 times at 55 ${ }^{\circ} \mathrm{C}$ through a polycarbonate membrane of $100 \mathrm{~nm}$ pore size (Mini-Extruder, Avanti Polar Lipids, Alabama, USA). The final molar concentration of liposomes was estimated from the mass concentration and the number of phospholipids and cholesterol molecules per liposome $(\mathrm{Nb})$. We assumed that liposomes were unilamellar and that there was no sample loss during liposome preparation. $\mathrm{Nb}$ was calculated from the diameter $(d)$ of liposomes as measured by DLS, the bilayer thickness $(e)$, and the phospholipid molecular area $(A)$ using eq 1.

$$
\mathrm{Nb}=\frac{4 \pi}{A}\left[\left(\frac{d}{2}\right)^{2}+\left(\frac{d}{2}-e\right)^{2}\right]
$$

Diameters of $\sim 50$ and $100 \mathrm{~nm}$ were measured for sonicated and extruded liposomes, respectively. Using $e=4 \mathrm{~nm}$ and $A=$ $40 \AA^{2}$, we found $\mathrm{Nb}=33,500$ for sonicated liposomes and 145,000 for extruded liposomes. Taking into account only the phospholipids in DPPC/DMPG/cholesterol liposomes, with an average $M_{\mathrm{W}}$ of $\sim 731 \mathrm{Da}$ and a mass concentration of 0.882 $\times 60 \mathrm{mg} \mathrm{mL}^{-1}$, we estimated concentrations to be $2.2 \mu \mathrm{M}$ for sonicated and $0.5 \mu \mathrm{M}$ for extruded liposomes.

To prepare loaded liposomes, the peptides were dissolved into the hydration buffer at a concentration of $10 \mathrm{mg} \mathrm{mL}^{-1}$, prior to the hydration step. Nonencapsulated peptides were removed by several successive dilution and centrifugation steps. The encapsulation efficiency, calculated as the amount of encapsulated peptides divided by the total amount of peptides used for sample preparation, was determined by HPLC (Waters 996-photodiode array detector, 210-285 $\mathrm{nm}$ detection) using a $\mathrm{C} 18$ column (Waters Xselect $\mathrm{CSH}$ ) heated at $60{ }^{\circ} \mathrm{C}$ and a water-acetonitrile gradient with $0.05 \%$ TFA.

2.4. NMR Sample Preparation. NMR samples were generally prepared in $80 \mathrm{mM}$ HEPES $\mathrm{pH} 7.4$ buffer with 100 $\mathrm{mM} \mathrm{NaCl}$. For chemical shift assignment, one sample was prepared in $20 \mathrm{mM}$ Tris- $d_{11} \mathrm{pH} 7.4$ and a second sample in 20 mM HEPES- $d_{18}$, where the $\mathrm{pH}$ was varied stepwise between $\mathrm{pH} 5.0$ and 7.4. The solvent was composed of $95 \% \mathrm{H}_{2} \mathrm{O}$, to observe labile protons such as amide protons, and $5 \% \mathrm{D}_{2} \mathrm{O}$, required to lock the magnetic field. Samples were filled into 3 or $5 \mathrm{~mm}$ NMR tubes. ${ }^{1} \mathrm{H}$ NMR spectra were acquired on different Bruker spectrometers: a $600 \mathrm{MHz}$ AVANCE III equipped with a TBI probe, a $600 \mathrm{MHz}$ AVANCE III HD with a TCI cryoprobe, a $700 \mathrm{MHz}$ NEO with a TXI standard probe, and an $800 \mathrm{MHz}$ AVANCE III HD with a TCI cryoprobe. All probes were triple resonance probes, equipped with $z$-axis gradients. Spectra were recorded at temperatures between 5 and $70{ }^{\circ} \mathrm{C}$. The temperature was carefully calibrated for all probes using Bruker standard tubes containing methanol or ethylene glycol for the different temperatures ranges. For 1D ${ }^{1} \mathrm{H}$ as well as $2 \mathrm{D}$ TOCSY and NOESY experiments, solvent (water) ${ }^{1} \mathrm{H}$ signal suppression was achieved by excitation sculpting. In such experiments, an $\sim 5-8 \mathrm{~ms}$ delay between spin excitation and detection is required for solvent suppression. This results in attenuation of the signal intensity at the beginning of detection due to transverse spin relaxation. Therefore, the measured signal integral of fast relaxing spins is smaller than that of slowly relaxing spins. TOCSY experiments were collected using the dipsi2esgpph Bruker pulse sequence (40 ms mixing time). NOESY experiments were collected using the noesyesgpph sequence ( $300 \mathrm{~ms}$ mixing time). To monitor lipid bilayer phase transitions, $1 \mathrm{D}{ }^{1} \mathrm{H}$ spectra were collected in a temperature range from 15 to $70{ }^{\circ} \mathrm{C}$ by $1-5^{\circ} \mathrm{C}$ increments. The reversibility of the transition was confirmed by returning to $20^{\circ} \mathrm{C}$. A delay of $10 \mathrm{~min}$ was applied after each temperature change to allow sample equilibration. Each $1 \mathrm{D}^{1} \mathrm{H}$ spectrum was collected during $5 \mathrm{~min}$. A total acquisition time of $9 \mathrm{~h}$ was needed to measure all spectra for temperature scanning. ${ }^{31} \mathrm{P}$ NMR spectra were acquired on a Bruker spectrometer $600 \mathrm{MHz}$ AVANCE III equipped with a liquid TBI probe. The zg30 pulse sequence was used with a $30^{\circ}$ pulse at $10.7 \mu$ s and a recycling delay of $3 \mathrm{~s}$, without ${ }^{1} \mathrm{H}$ decoupling since ${ }^{1} \mathrm{H}$ decoupling did not improve sensitivity. ${ }^{31} \mathrm{P}$ chemical shifts were calibrated using $85 \%$ phosphoric acid ( $0 \mathrm{ppm})$ in water. ${ }^{19} \mathrm{~F}$ NMR spectra were recorded on a Bruker spectrometer $600 \mathrm{MHz}$ AVANCE III equipped with a QCIF $5 \mathrm{~mm}$ cryoprobe. ${ }^{19} \mathrm{~F}$ chemical shifts were referenced internally with $100 \mu \mathrm{M}$ 3-fluoro-4-methylbenzamidine (-114.7 ppm). ${ }^{47}$ All $1 \mathrm{D}$ and $2 \mathrm{D}$ data were processed with TopSpin (Bruker) and analyzed using TopSpin or CcpNmr Analysis ${ }^{48}$ software.

2.5. Diffusion-Ordered Spectroscopy (DOSY). A bipolar pulse pair stimulated echo NMR pulse sequence was modified to allow water suppression by excitation sculpting and by addition of a delay to attenuate longitudinal eddy current effects as proposed by ref 49 . The diffusion delay $\Delta$ was set to $800 \mathrm{~ms}$ to account for the large range of diffusion rates of small molecules and liposomes. The coding/decoding gradients had a length $\delta$ of $1500 \mu \mathrm{s}$, and gradient intensity $g$ was varied from 2 to $98 \%$ of the maximal value $\left(50 \mathrm{G} \mathrm{cm}^{-1}\right)$. DOSY spectra were processed using TopSpin and Dynamics Center software (Bruker BioSpin) and analyzed with the oneor two-component Stejskal-Tanner equation ${ }^{50}$

$$
f(g)=I_{01} \mathrm{e}^{-\gamma^{2} g^{2} \delta^{2}(\Delta-\delta / 3) \times D 1}+I_{02} \mathrm{e}^{-\gamma^{2} g^{2} \delta^{2}(\Delta-\delta / 3) \times D 2}
$$

where $I_{0 i}(i=1$ and 2$)$ is the intensity at $0 \%$ gradient strength, $\gamma$ is the ${ }^{1} \mathrm{H}$ gyromagnetic ratio, $g$ is the gradient strength, $\delta$ is the gradient length, $\Delta$ is the diffusion delay, and $D i$ the translational diffusion coefficient $\left(\mathrm{m}^{2} \mathrm{~s}^{-1}\right)$.

2.6. Dynamic Light Scattering. Dynamic light scattering measurements (DLS) were performed with a $173^{\circ}$ angle on a Zetasizer Nano $S$ instrument (Malvern). Liposome samples were diluted in $80 \mathrm{mM}$ HEPES pH 7.4 and $100 \mathrm{mM} \mathrm{NaCl}$ buffer with a $1 / 250 \mathrm{v} / \mathrm{v}$ ratio $(330 \mu \mathrm{M}$ final concentration of lipids) and measured in disposable $70 \mu \mathrm{L}$ cuvettes (Brand, Z637092). Measurements were carried out either at $25^{\circ} \mathrm{C}$ or in a range between 20 and $60^{\circ} \mathrm{C}$, by a stepwise increase or decrease of temperature by $1{ }^{\circ} \mathrm{C}$. For analysis with Zetasizer software, the solvent was set to water, the material refractive index to 1.450 , the medium refractive index to 1.330 , and the medium dynamic viscosity to $0.8872 \mathrm{cP}$ at $25^{\circ} \mathrm{C}$.

2.7. Cryo-Electron Transmission Microscopy. Lipid suspensions were $1 / 10$ water-diluted and $4 \mu \mathrm{L}$ deposited on a 
A
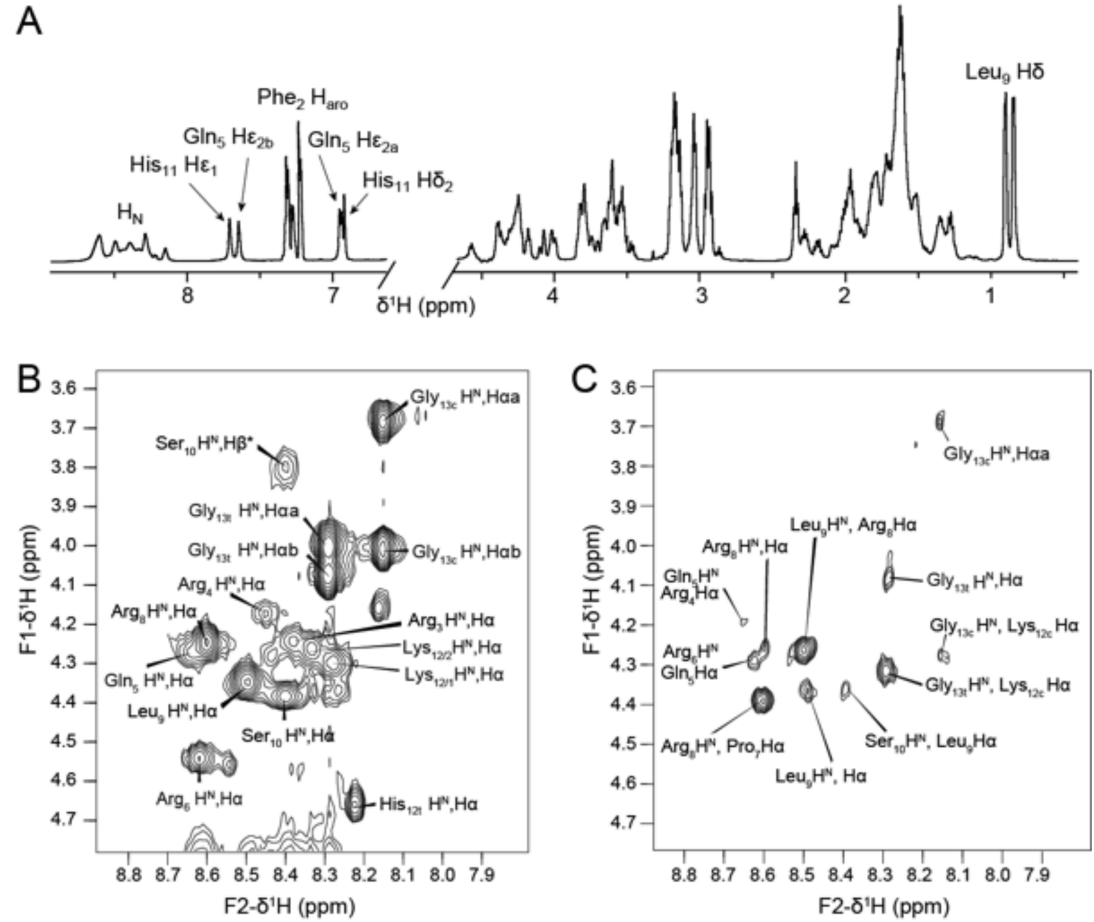

Figure 1. 1D and 2D ${ }^{1} \mathrm{H}$ NMR spectra of $\mathrm{K} 14 \mathrm{P}$ with chemical shift assignments at $\mathrm{pH} 7.4$ and $5{ }^{\circ} \mathrm{C}$. Measurements were done at $600 \mathrm{MHz}{ }^{1} \mathrm{H}$ frequency with a sample containing $350 \mu \mathrm{M}$ K14P in $20 \mathrm{mM}$ Tris-d11 pH 7.4 buffer. (A) $1 \mathrm{D}{ }^{1} \mathrm{H}$ NMR spectrum with water suppression showing all K14P signals. Only the NMR resonances that were well-separated in the 1D spectrum are labeled. The complete assignment is available Supplementary Table 2. (B) Close-up of the $2 \mathrm{D}{ }^{1} \mathrm{H}-{ }^{1} \mathrm{H}$ TOCSY spectrum $(\tau \mathrm{m}=40 \mathrm{~ms})$ centered on the amide $\left({ }^{1} \mathrm{H}^{\mathrm{N}}\right)$ region in the F2 dimension and ${ }^{1} \mathrm{H} \alpha$ in the $\mathrm{F} 1$ dimension. Signal assignments of the intraresidual $\mathrm{H}^{\mathrm{N}}, \mathrm{H} \alpha$ correlations are indicated for each amino acid residue. Signals from peptides bearing trans or cis Pro 14 isomers are denoted $\mathrm{t}$ or $\mathrm{c}$. (C) Close-up of the $2 \mathrm{D}{ }^{1} \mathrm{H}-{ }^{1} \mathrm{H}$ NOESY spectrum $(\tau \mathrm{m}=300 \mathrm{~ms})$ in the same spectral region showing sequential $\mathrm{H}^{\mathrm{N}}{ }_{i} \mathrm{H} \alpha_{i-1}$ and intraresidual $\mathrm{H}^{\mathrm{N}}{ }_{i} \mathrm{H} \alpha_{i}$ NOE cross peaks used for sequential resonance assignment. Some $2 \mathrm{D}$ correlation peaks are absent in the $2 \mathrm{D}$ spectra at $\mathrm{pH} 7.4$ due to fast proton exchange with solvent, but they were clearly visible at $\mathrm{pH} 5.0$ (see Supplementary Figure 1).

200 mesh holey carbon-coated grid. After blotting with filter paper, the grid was frozen by rapid plunging in liquid ethane and was mounted and inserted in the microscope using a nitrogen-cooled side entry Gatan 626 cryo-holder at a temperature of $-178{ }^{\circ} \mathrm{C}$. Observations were carried out in a Thermo Fisher Titan Themis 300 transmission electron microscope equipped with a cryo-box anticontamination system and a C-Twin objective lens (Cs, $2.7 \mathrm{~mm}$; Cc, 2.0 $\mathrm{mm}$ ), using an accelerating voltage of $300 \mathrm{kV}$, with the following illumination conditions: spot size of 3, a $150 \mu \mathrm{m}$ condenser aperture, and a $70 \mu \mathrm{m}$ motorized objective aperture. Images were recorded (defocus range, -1.2 to $-2.0 \mu \mathrm{m}$ ), using the low electron dose system ( 10 electrons per $\AA^{2}$ per s), with a magnification range from $20,000 \times$ to $60,000 \times$ on a Falcon 3 Direct Detection Electron $4 \mathrm{Kx} 4 \mathrm{~K}$ camera in the linear mode.

\section{RESULTS AND DISCUSSION}

3.1. Solution Structure and Self-Organization of Apelin K14P Peptides by ${ }^{1} \mathrm{H}$ NMR. 3.1.1. Solution Structure of Apelin K14P Peptides by ${ }^{1} H$ NMR. Due to their structural plasticity, peptides may not have a well-defined secondary or tertiary structure but may remain unstructured or adopt multiple conformations. This affects molecular interactions and must be considered for encapsulation into drug delivery systems like liposomes. NMR is a well-established tool for the structural characterization of small molecules and proteins, including peptides, at the secondary and at the $3 \mathrm{D}$ structural levels. ${ }^{51}$ We thus started by investigating the apelin $\mathrm{K} 14 \mathrm{P}$ peptide in solution by ${ }^{1} \mathrm{H}$ NMR.
The ${ }^{1} \mathrm{H}$ NMR spectrum of $\mathrm{K} 14 \mathrm{P}$ measured in protonated buffer $\left(95 \%: 5 \% \mathrm{H}_{2} \mathrm{O} / \mathrm{D}_{2} \mathrm{O}\right)$ at physiological $\mathrm{pH} 7.4$ and at 5 ${ }^{\circ} \mathrm{C}$ is shown in Figure 1A. Under these conditions, several amide ${ }^{1} \mathrm{H}_{\mathrm{N}}$ signals, which usually fall in the 6-9 ppm range, were severely broadened due to exchange with water protons. This was even more marked at $25{ }^{\circ} \mathrm{C}$ (Supplementary Figure 1A). We thus performed subsequent NMR measurements preferentially at $5{ }^{\circ} \mathrm{C}$.

To detect all K14P ${ }^{1} \mathrm{H}$ signals, we performed NMR acquisitions on a sample at $\mathrm{pH} 5$ and $5{ }^{\circ} \mathrm{C}$ (Supplementary Figure 1). At low temperature and low $\mathrm{pH}$, chemical exchange between labile ${ }^{1} \mathrm{H}^{\mathrm{N}}$ and water is slowed down, which results in narrower ${ }^{1} \mathrm{H}^{\mathrm{N}}$ signals and in turn in larger signal intensities. 2D ${ }^{1} \mathrm{H}-{ }^{1} \mathrm{H}$ TOCSY experiments were used to correlate protons within each spin system defined by an amino acid side chain. $2 \mathrm{D}{ }^{1} \mathrm{H}-{ }^{1} \mathrm{H}$ NOESY spectra were used to detect through-space proximities between hydrogens. The combined analysis of these $2 \mathrm{D}$ spectra ${ }^{51}$ allowed sequential assignment of all ${ }^{1} \mathrm{H}$ signals to their corresponding atoms (Supplementary Table 1). Assignments at $\mathrm{pH} 7.4$ (Supplementary Table 2) were then obtained by following signals throughout a $\mathrm{pH}$ titration from 5.0 up to 7.4 and confirmed with $2 \mathrm{D}$ TOCSY and NOESY spectra recorded at $\mathrm{pH} 7.4$ and $5{ }^{\circ} \mathrm{C}$ (Figure 1B,C). Signal intensities of carbon-attached ${ }^{1} \mathrm{H}$ remained high over the whole $\mathrm{pH}$ range since they do not suffer from solvent exchange. Of note, K14P exhibited two sets of chemical shifts for three amino acid residues upstream of $\mathrm{Pro}_{14}$ (Supplementary Tables 1 and 2). They correspond to trans and cis conformations of the $\mathrm{Gly}_{13}-\mathrm{Pro}_{14}$ peptide bond, as judged from 

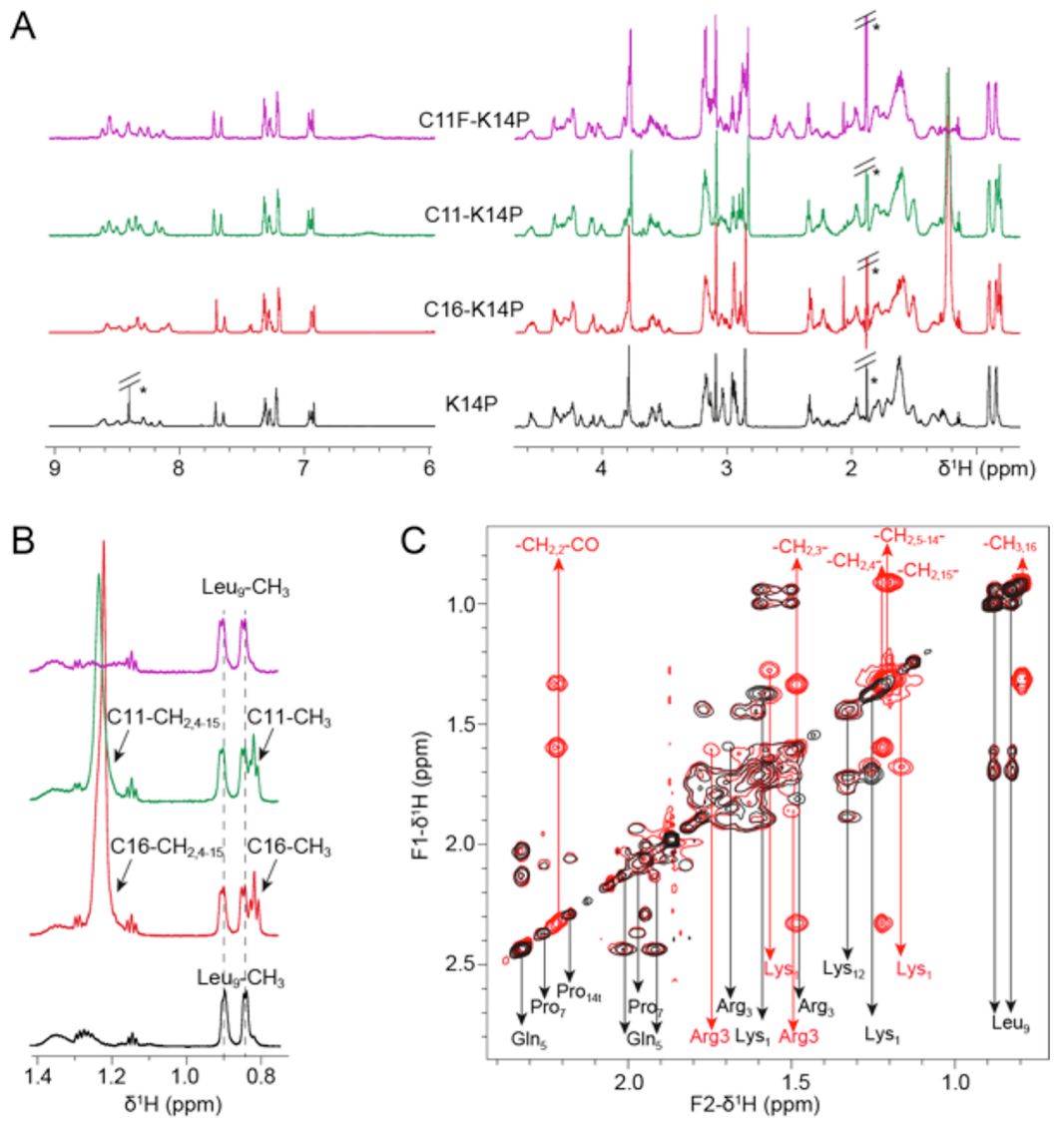

Figure 2. ${ }^{1} \mathrm{H}$ NMR spectra of fatty acylated K14P below their CMC as compared to K14P. (A) $1 \mathrm{D}{ }^{1} \mathrm{H}$ NMR spectra of K14P, C16-K14P, C11$\mathrm{K} 14 \mathrm{P}$, and C11F-K14P measured in $80 \mathrm{mM}$ HEPES- $d_{18} \mathrm{pH} 7.4$ buffer in $95 \% \mathrm{H}_{2} \mathrm{O} / 5 \% \mathrm{D}_{2} \mathrm{O}$, at $5{ }^{\circ} \mathrm{C}$ and at $800 \mathrm{MHz}{ }^{1} \mathrm{H}$ frequency for K14P $(350$ $\mu \mathrm{M})$ and $700 \mathrm{MHz}$ for $\mathrm{N} \alpha$-acylated variants $(200 \mu \mathrm{M})$. Signals indicated by stars correspond to acetate counterions $(1.85 \mathrm{ppm})$ and an impurity $(8.4 \mathrm{ppm})$. (B) Close-up of superimposed ${ }^{1} \mathrm{H}$ NMR spectra disclosing fatty acid-specific methylene and methyl signals. Of note, the fluorinated $\mathrm{CF}_{2} / \mathrm{CF}_{3}$ positions in C11F-K14P do not give signals in the corresponding (magenta) ${ }^{1} \mathrm{H}$ spectrum. (C) Superimposition of the TOCSY spectra $(\tau \mathrm{m}=40 \mathrm{~ms})$ of $\mathrm{K} 14 \mathrm{P}$ (black) and $\mathrm{C} 16-\mathrm{K} 14 \mathrm{P}$ (red). In this region, ${ }^{1} \mathrm{H}-{ }^{1} \mathrm{H}$ correlations between and within methylene and methyl groups of the C16-fatty acid moiety are visible.

the analysis of sequential nuclear Overhauser effects (NOE) between $\mathrm{Gly}_{13}$ and Pro $_{14}$ (Supplementary Figure 1B,C). Using the approximation that the NMR signal intensities are proportional to the relative populations of each conformation, the relative trans/cis ratio was estimated to be $75: 25$. The $\mathrm{Pro}_{14}$ cis/trans equilibrium had also been observed for longer apelin fragments. ${ }^{42,52}$

The $1 \mathrm{D}{ }^{1} \mathrm{H}$ spectrum in Figure 1A shows a strong signal overlap in the aliphatic proton region (1-5 ppm). However, a few signals of aromatic and $\mathrm{NH}_{2}$ side chain protons (6.5-8 $\mathrm{ppm})$ as well as the two $\mathrm{Leu}_{9}$ methyl groups $(\sim 0.8-0.9 \mathrm{ppm})$ were generally well-separated from other peptide, buffer, or lipid signals. We could advantageously use these signals to report on peptide behavior in more complex environments, even in the presence of nondeuterated buffer and lipids. Aromatic and methyl-containing amino acid residues are hence convenient NMR probes to characterize peptides in complex environments.

Chemical shift values encode structural information as they report on the local electronic environment of each observed nucleus. In particular, peptide backbone chemical shifts report on local secondary structure propensity. For random coil conformation, they can be predicted by using tools based on statistics driven from comparison between protein chemical shifts and structure databases. For K14P, experimental residue- specific ${ }^{1} \mathrm{H} \alpha$ chemical shifts were in the range of values predicted for random coil conformation (Supplementary Tables 1 and $2^{53}$ ). This suggests that $\mathrm{K} 14 \mathrm{P}$ is largely unstructured in solution with no stable secondary structure. The absence of secondary or tertiary structures is corroborated by the absence of medium- or long-range NOEs: all detected NOEs were exclusively intraresidual or sequential $(i, i+1)$. These results are in line with circular dichroism and NMR data reported on cognate apelin peptides, which indicated that they were mainly random coils. ${ }^{42}$

3.1.2. Influence of $N \alpha$-Fatty Acylation on the Structure of K14P. Self-assembly might impact peptide-liposome interactions and in turn modulate formation of loaded liposomes as well as subsequent release kinetics. Chemical modifications such as fatty acylation of peptides are expected to drive selfassembly. We thus characterized the impact of $\mathrm{N} \alpha$-fatty acylation with hexadecanoic (C16), undecanoic (C11), or partially fluorinated $(\mathrm{C} 11 \mathrm{~F})$ undecanoic acids on the structure of K14P peptides by NMR (Figure 2A). We first worked at submicellar concentration $\left(200 \mu \mathrm{M}\right.$, see below). Peptide ${ }^{1} \mathrm{H}$ signals superimposed almost perfectly with those of K14P at 5 ${ }^{\circ} \mathrm{C}$ and $\mathrm{pH}$ 7.4. This greatly facilitated the transfer of the chemical shift assignments from K14P to the three variants, C16-K14P, C11-K14P, and C11F-K14P. Assignments were confirmed by 2D TOCSY spectra (Figure 2B). Chemical shift 
A $[K 14 \mathrm{P}]$
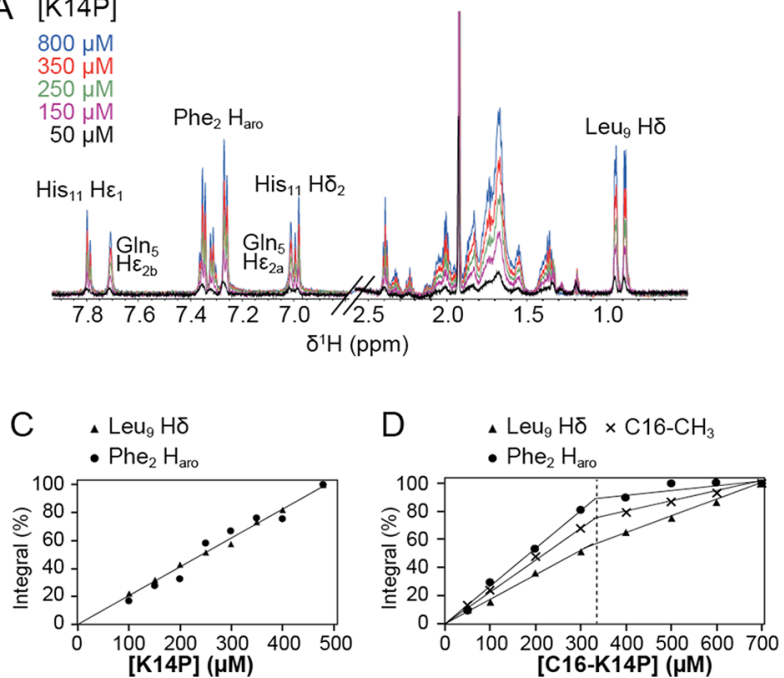
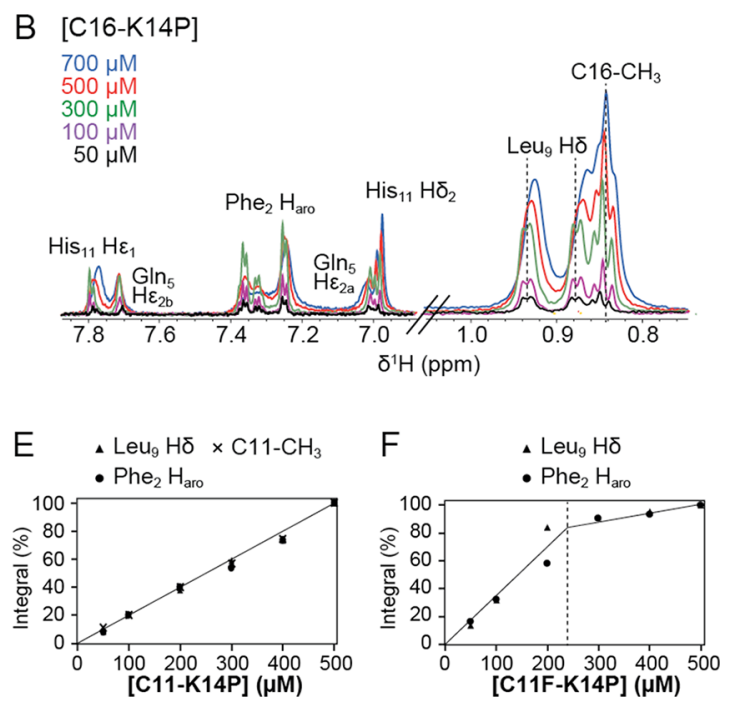

Figure 3. Evolution of ${ }^{1} \mathrm{H}$ NMR spectra of $\mathrm{K} 14 \mathrm{P}$ peptides and $\mathrm{N} \alpha$-acylated $\mathrm{C} 11-, \mathrm{C} 11 \mathrm{~F}-$, and C16-K14P with increasing peptide concentration. $(\mathrm{A}, \mathrm{B})$ Superimposition of ${ }^{1} \mathrm{H}$ NMR spectra of $\mathrm{K} 14 \mathrm{P}$ and $\mathrm{C} 16-\mathrm{K} 14 \mathrm{P}$ at different peptide concentrations collected in $80 \mathrm{mM}$ HEPES pH 7.4 and 100 $\mathrm{mM} \mathrm{NaCl}$ buffer in $95 \% \mathrm{H}_{2} \mathrm{O} / 5 \% \mathrm{D}_{2} \mathrm{O}$ at $5{ }^{\circ} \mathrm{C}$ and at $700 \mathrm{MHz}{ }^{1} \mathrm{H}$ frequency. (C-F) Integrals of selected ${ }^{1} \mathrm{H} 1 \mathrm{D}$ NMR signals $\left(\mathrm{Leu}_{9} \mathrm{H} \delta\right.$, Phe ${ }_{2}$ $\mathrm{H}_{\text {aro }}$, and when available fatty acyl chain $\mathrm{CH}_{3}$ ), normalized to the integral value measured at the highest peptide concentration, plotted as a function of concentration. Straight lines correspond to linear regressions for each proton signal. CMC values were measured at the position of slope changes, indicated by broken lines.

variations were mainly observed at the $\mathrm{N}$-terminus of K14P. $\mathrm{Lys}_{1}$ showed the largest chemical shift deviations, when comparing acylated forms with K14P (Supplementary Figure 2 ). This was expected since $\mathrm{N} \alpha$-fatty acylation was carried out on Lys ${ }_{1}$. The results suggest that acylation did not modify the overall structure of the peptide part. Moreover, NMR signals were narrow at $200 \mu \mathrm{M}$ concentration, suggesting that under these conditions, the acylated peptides were essentially monomeric.

For $\mathrm{C} 16-\mathrm{K} 14 \mathrm{P}$ and $\mathrm{C} 11-\mathrm{K} 14 \mathrm{P}$, the $\mathrm{CH}_{3}$ and $\mathrm{CH}_{2}$ fatty acyl chain groups gave typical signals at $\sim 0.8$ and $1.2 \mathrm{ppm}$, respectively (Figure $2 \mathrm{~B}$ ). In $\mathrm{C} 11 \mathrm{~F}-\mathrm{K} 14 \mathrm{P}$, these positions were fluorinated and hence not visible in ${ }^{1} \mathrm{H}$ spectra. Signals from the fatty acid moiety were also identified as additional signals in the ${ }^{1} \mathrm{H}-{ }^{1} \mathrm{H}$ TOCSY spectra of the $\mathrm{K} 14 \mathrm{P}$ variants when compared to K14P (Figure 2B). At $200 \mu \mathrm{M}$ concentration, the fatty acyl signals were also narrow, confirming the monomeric state of the fatty-acylated peptide. No long-range NOEs were observed in 2D NOESY spectra, neither within the fatty acyl group nor between the fatty acyl and peptide groups. This indicated that the acylated peptides C16-K14P and C11-K14P remained mainly disordered in solution.

3.1.3. Monitoring Micelle Formation of $N \alpha$-Acylated K14P. The linewidth of a ${ }^{1} \mathrm{H}$ NMR signal is highly sensitive to molecular reorientation. When broad signals are observed all along a molecule, this is usually indicative of slow molecular tumbling and typical for molecules of large molecular weight. Ultimately, very slow tumbling of large molecules results in nonobservable signals. This is particularly true when NMR experiments contain efficient water-suppression elements, as required when working with $\mathrm{H}_{2} \mathrm{O}$-dissolved peptides. In the case of micelle formation, when the exchange between monomeric and micellar species is faster than the chemical shift difference for a given ${ }^{1} \mathrm{H}$ in the two species (typically at the $\sim$ ms timescale), a single NMR signal is observed at the population-averaged chemical shift and with a populationaveraged linewidth. Consequently, micelle formation impacts spectra by decreased signal intensities and increased line- widths. Below the critical micellar concentration (CMC), signal linewidths are constant, and signal intensities and integrals increase linearly with concentration. However, at concentrations above the $\mathrm{CMC}$, linewidths increase, and signal intensities/integrals are still proportional to the total concentration but with a different slope due to the distinct ${ }^{1} \mathrm{H}$ linewidths in the monomer and micelle states. Due to the filter effect of the water signal suppression, signal intensities/ integrals show a discontinuity when they are plotted versus concentration, which allows retrieving CMC values. ${ }^{54}$

To probe self-association of K14P and its variants, we explored the concentration dependence of ${ }^{1} \mathrm{H}$ NMR spectra with respect to linewidths and signal integrals in $80 \mathrm{mM}$ HEPES pH 7.4 and $100 \mathrm{mM} \mathrm{NaCl}$ buffer. For all signals in K14P (Figure 3A,C) and C11-K14P (Figure 3E), signal integrals increased proportionally to a concentration of up to $500 \mu \mathrm{M}$, without any detectable change in linewidths or chemical shifts. Signals were relatively narrow, suggesting that these two peptides were predominantly monomeric at concentrations below $500 \mu \mathrm{M}$.

At concentrations below $300 \mu \mathrm{M}, \mathrm{C} 16-\mathrm{K} 14 \mathrm{P}$ and $\mathrm{C} 11 \mathrm{~F}$ $\mathrm{K} 14 \mathrm{P}$ displayed similar behaviors. However, at higher concentrations, there was a transition in the evolution of signal integrals as a function of concentration (Figure 3B, D, and F). Linewidths increased concomitantly, and the fine structure of the spectra was smeared out (Figure 3B). This is indicative of formation of soluble high-molecular-weight objects. Due to the amphiphilicity of C16-K14P and C11F$\mathrm{K} 14 \mathrm{P}$ peptides, we hypothesized that these objects are micelles. We therefore assimilated the transition concentration, determined from the signal integral evolution, to a CMC (Figure 3D,F and Table 1).

To further confirm self-association, we performed size measurements by DLS at high peptide concentration, i.e., $500 \mu \mathrm{M}$ (Table 1 and Supplementary Figure 3). We compared them with the lengths of $\mathrm{K} 14 \mathrm{P}, \mathrm{C} 11-\mathrm{K} 14 \mathrm{P}$, and $\mathrm{C} 16-\mathrm{K} 14 \mathrm{P}$ in a fully extended conformation, which are $\sim 4,5$, and $5.5 \mathrm{~nm}$, 
Table 1. Apparent Size (Diameter) at $500 \mu \mathrm{M}$ of K14P and No-Acylated C11-, C11F-, and C16-K14P Peptides and Critical Micellar Concentration ${ }^{a}$

\begin{tabular}{lcl}
\multicolumn{1}{c}{ peptide } & apparent size $(\mathrm{nm})$ at $500 \mu \mathrm{M}$ & $\mathrm{CMC}(\mu \mathrm{M})$ \\
K14P & $1 \pm 2 \mathrm{~nm}$ & $>500$ \\
$\mathrm{C} 11-\mathrm{K} 14 \mathrm{P}$ & $1 \pm 2 \mathrm{~nm}$ & $>500$ \\
$\mathrm{C} 16-\mathrm{K} 14 \mathrm{P}$ & $9 \pm 2 \mathrm{~nm}$ & $330 \pm 10$ \\
$\mathrm{C} 11 \mathrm{~F}-\mathrm{K} 14 \mathrm{P}$ & $12 \pm 1 \mathrm{~nm}$ & $250 \pm 50$
\end{tabular}

${ }^{a}$ Sizes were determined from DLS measurements at $25^{\circ} \mathrm{C}$ in $80 \mathrm{mM}$ HEPES pH $7.4100 \mathrm{mM} \mathrm{NaCl}$ buffer, using the size distribution by volume option in Zetasizer software. The peak with the smaller size was assigned to the peptide. CMC values were obtained by NMR signal integral measurements as shown in Figure 3. For K14P and $\mathrm{C} 11-\mathrm{K} 16 \mathrm{P}$, only a lower CMC estimate is provided.

respectively. The small size, $1 \pm 2 \mathrm{~nm}$, determined for $\mathrm{K} 14 \mathrm{P}$ and $\mathrm{C} 11-\mathrm{K} 14 \mathrm{P}$ suggests that these peptides stay monomeric below $500 \mu \mathrm{M}$. For C16-K14P and C11F-K14P, sizes were measured in the $10 \mathrm{~nm}$ range. This points to an increased apparent size for C16-K14P and C11F-K14P at a concentration above the CMC, which is consistent with self-assembly and NMR line broadening observed only for C16-K14P and C11F-K14P. Taken together, these results confirm that $\mathrm{C} 16$ and $\mathrm{C} 11 \mathrm{~F}$ acylations result in significant stabilization of micelles and that fluorination of C11 lowers the CMC as compared to protonated C11 acylation. This is in line with increased hydrophobicity due to fatty acid chain length and fluorination.

3.2. Structural Characterization of Empty Liposomes. 3.2.1. Characterization of Liposome Preparations by CryoTEM and DLS. With the aim to encapsulate K14P peptides in liposomes and to monitor the impact of encapsulation on the liposome structure, we first prepared empty DPPC/DMPG liposomes, ${ }^{46}$ without and with $11.8 \%$ cholesterol, either by sonication or by extrusion. We characterized their size, shape, and lamellarity by cryo-TEM, ${ }^{55-58}$ and we measured particle sizes and polydispersity by DLS. ${ }^{59}$

We observed different liposomal preparations with cryoTEM (Figure 4). Sonicated liposomes were exclusively small unilamellar vesicles (SUVs) (Figure 4A). In contrast, extruded liposomes contained a mixture of $\sim 60 \%$ SUVs and $\sim 40 \%$ multilayered, mostly bilamellar, vesicles (Figure 4B). Under our conditions, the average number of bilayers thus varied with the liposome preparation method. Moreover, extruded lip- osomes prepared without cholesterol showed many irregularities, in particular edges (Figure 4C), suggesting that cholesterol induced more rigid and less deformable membranes and hence favored nearly spherical shapes for the cholesterolcontaining liposomes. The irregularities might be related to the distribution of phospholipids in the bilayer and packing defects. ${ }^{60}$ Based on the cryo-TEM images, we measured the averaged diameters and the polydispersity indexes (PdI) of the cholesterol-containing particles: $49 \pm 19 \mathrm{~nm}$ (PdI, 0.15) for sonicated and $102 \pm 34 \mathrm{~nm}$ (PdI, 0.11) for extruded cholesterol-containing liposomes (Supplementary Figure 4). In the absence of cholesterol, the particles size of extruded liposomes was $67 \pm 20 \mathrm{~nm}$ with a PdI of 0.09 . The PdI values from cryo-TEM images were calculated from the average particle size $m$ and its standard deviation $\sigma$ as $(\sigma / m){ }^{2}$

By DLS, using the $Z$-average method, we determined an average size of $77 \pm 31 \mathrm{~nm}$ (PdI, 0.16) for sonicated liposomes and $120 \pm 2 \mathrm{~nm}$ (PdI, 0.09) for extruded liposomes (Supplementary Figure 3). This is in agreement with the cryo-TEM results that showed that sonicated liposomes were smaller than extruded liposomes prepared in this study. However, the absolute size values differed between the two techniques, possibly due to overestimation of the large particle contribution in DLS measurements and to exclusion of large particles in cryo-EM grids.

3.2.2. Characterization of Membrane Fluidity in Liposomal Preparations by ${ }^{31} \mathrm{P}$ and ${ }^{7} \mathrm{H} N \mathrm{~N}$ R. Static wide-line and magic-angle spinning ${ }^{31} \mathrm{P},{ }^{2} \mathrm{H}$, and ${ }^{1} \mathrm{H}$ NMR have been extensively used to study phospholipid bilayer organization and dynamics. ${ }^{61,62}$ More specifically, ${ }^{31} \mathrm{P}$ NMR reports on the local environment and mobility of phospholipid head groups, whereas ${ }^{1} \mathrm{H}$ NMR reports on the mobility of both head groups and lipid chains. Here, we probed liposomal membrane dynamics by static ${ }^{31} \mathrm{P}$ and ${ }^{1} \mathrm{H}$ NMR.

${ }^{31} \mathrm{P}$ NMR spectra were first collected at $5{ }^{\circ} \mathrm{C}$, well below the phase transition temperature $T_{\mathrm{m}}$ of the phospholipids used for liposome preparation: $41^{\circ} \mathrm{C}$ for DPPC and $23{ }^{\circ} \mathrm{C}$ for DMPG. At this temperature, the lipid bilayers were in the gel phase. The ${ }^{31} \mathrm{P}$ NMR spectrum of extruded liposomes consisted of a broad $(\sim 80 \mathrm{ppm}){ }^{31} \mathrm{P}$ signal with an asymmetric shape (Figure 5A). This NMR signal is typical for solid-state samples: the large linewidth and the anisotropic shape of the signal result from the ${ }^{31} \mathrm{P}$ chemical shift anisotropy (CSA) that is not averaged out to zero averaged here, neither by molecular motion nor by magic-angle spinning. It is therefore consistent
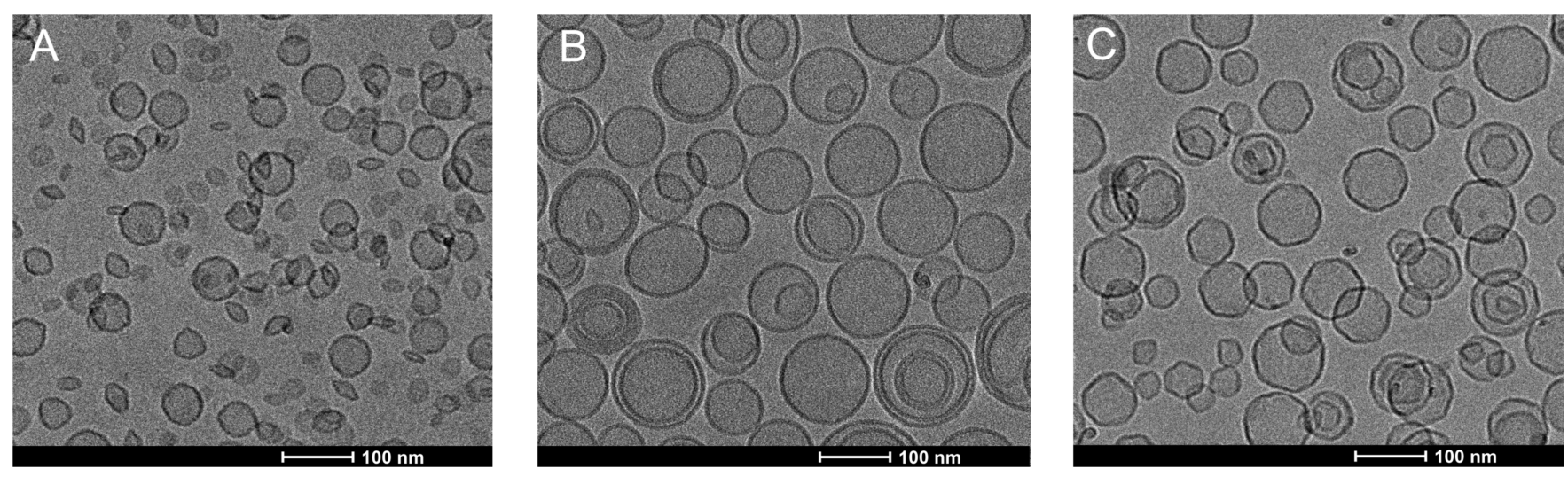

Figure 4. Cryo-TEM images of (A) blank sonicated and (B) extruded liposomes prepared with $11.8 \%$ cholesterol and of (C) blank extruded liposomes prepared without cholesterol. The scale is given by the bar for $100 \mathrm{~nm}$. 

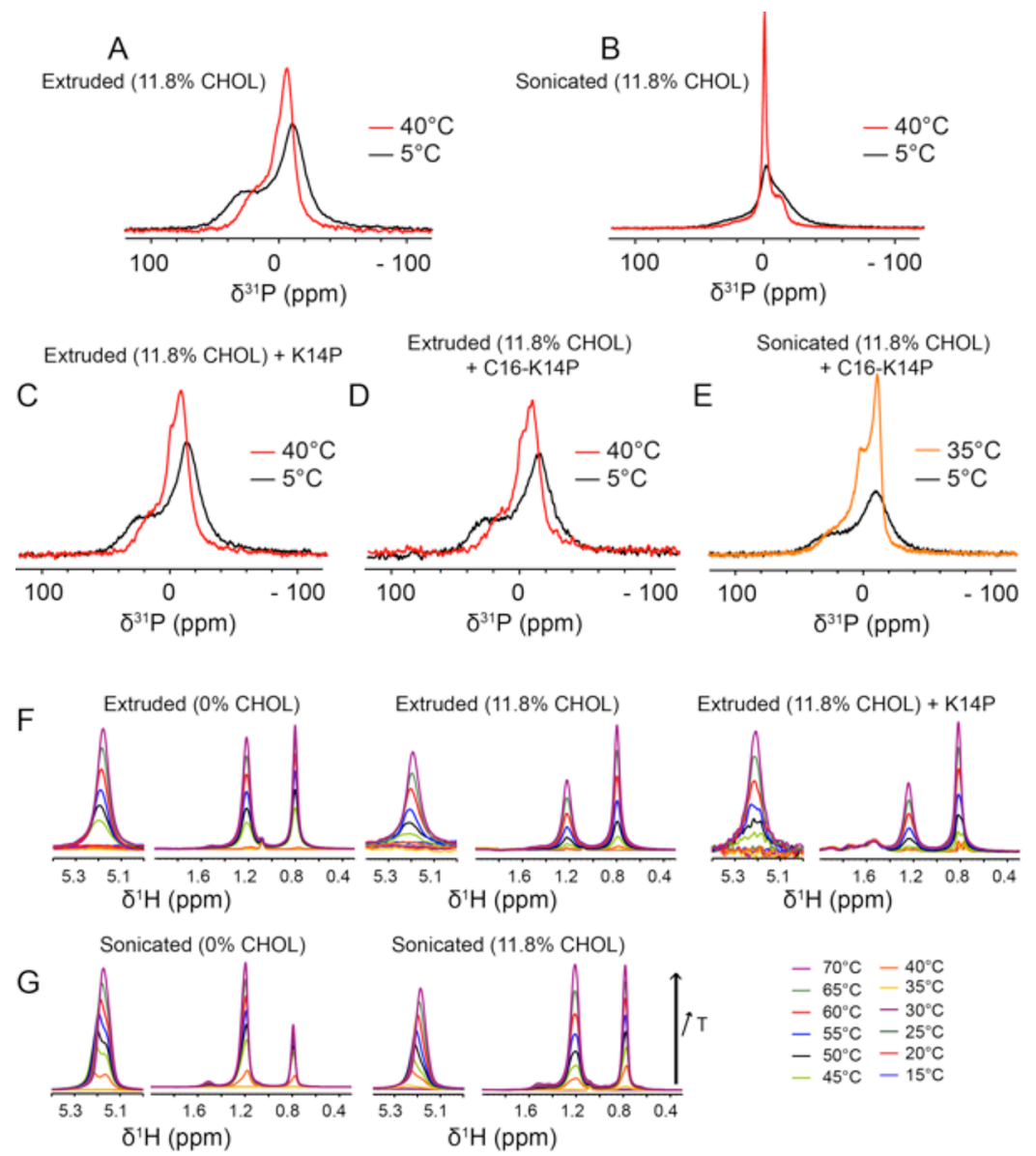

Figure 5. ${ }^{31} \mathrm{P}$ and ${ }^{1} \mathrm{H}$ NMR spectra of blank and peptide-loaded liposomes at different temperatures. Samples were in $80 \mathrm{mM}$ HEPES pH 7.4 and $100 \mathrm{mM} \mathrm{NaCl}$ buffer. (A,B) ${ }^{31} \mathrm{P}$ NMR spectra of DPPC/DMPG/cholesterol liposomes prepared by extrusion and sonication, respectively, at 5 and $40{ }^{\circ} \mathrm{C}$. (C,D) ${ }^{31} \mathrm{P}$ NMR spectra of extruded liposomes loaded with K14P and C16-K14P, respectively, at 5 and $40{ }^{\circ} \mathrm{C}$. (E) ${ }^{31} \mathrm{P}$ NMR spectra of sonicated C16-K14P-loaded liposomes at 5 and $35{ }^{\circ} \mathrm{C}$. Acquisition was done at $243 \mathrm{MHz}{ }^{31} \mathrm{P}$ frequency. (F,G) ${ }^{1} \mathrm{H}$ NMR spectra of extruded (F) and sonicated $(\mathrm{G})$ liposomes, with or without cholesterol, blank or loaded with $\mathrm{K} 14 \mathrm{P}$, measured at $600 \mathrm{MHz}{ }^{1} \mathrm{H}$ frequency and at different temperatures between 15 and $70{ }^{\circ} \mathrm{C}$. The regions are centered on the phospholipid glycerol backbone $\mathrm{H} 2$ " $(5.2 \mathrm{ppm})$, fatty acyl $\mathrm{CH}_{2}(1.2 \mathrm{ppm})$, and $\mathrm{CH}_{3}(0.8 \mathrm{ppm})$ signals. At temperatures below $35^{\circ} \mathrm{C}$, the phospholipid signals are essentially invisible, whereas upon heating, their intensities drastically increase.

with restricted motion of the phospholipid head groups in the gel phase and with the very slow tumbling of the large $100 \mathrm{~nm}$ sized liposomes. Sonicated liposomes, measured under the same conditions, gave a ${ }^{31} \mathrm{P}$ NMR signal with two components (Figure 5B). The first component was similar to the anisotropic signal of extruded liposomes. We assigned it to large liposomes in the gel phase. The second nearly symmetric component was centered at a chemical shift of $\sim 0 \mathrm{ppm}$ and had a narrower linewidth of $\sim 10 \mathrm{ppm}$ (Figure $5 \mathrm{~B}$ ). In this component, the ${ }^{31} \mathrm{P}$ CSA is highly, but incompletely, averaged out to zero by rapid motions and can therefore be considered to be isotropic. It is compatible with the signal of liposomes that are significantly smaller than $100 \mathrm{~nm}$ and tumble more rapidly. This is in agreement with the smaller average size observed by cryo-TEM (Figure 4) and DLS for sonicated liposomes, when compared to extruded liposomes. However, we cannot rule out that the sonicated liposomes contain subdomains within bilayers with more rapid motions.

When the temperature was increased to $40{ }^{\circ} \mathrm{C}$, close to the $T_{\mathrm{m}}$ of DPPC, the broad ${ }^{31} \mathrm{P}$ signal narrowed to $\sim 50 \mathrm{ppm}$ for extruded liposomes (Figure 5A) as well as for sonicated liposomes (Figure 5B). This reflects partial averaging of chemical shift anisotropy due to increased fluidity of the lipid bilayer and a transition from the gel to liquid-crystalline phase. For sonicated liposomes, the second isotropic component also narrowed, resulting in a marked intensity increase. This behavior can be linked both to increased bilayer fluidity and to more rapid overall tumbling of small lipid vesicles at higher temperatures.

To get further insight into the influence of temperature on liposome NMR spectra, we also collected $1 \mathrm{D}{ }^{1} \mathrm{H}$ NMR spectra at various temperatures, below, near to, and above the expected main transition temperature $\left(\sim 40{ }^{\circ} \mathrm{C}\right)$. For extruded liposomes at $5{ }^{\circ} \mathrm{C}$, the ${ }^{1} \mathrm{H}$ signals from phospholipids and cholesterol were too broad to be detected (Figure 5E). The vanishing ${ }^{1} \mathrm{H}$ signals can be easily explained by the slow tumbling of large particles, and the absence of internal motions, that make ${ }^{1} \mathrm{H}-{ }^{1} \mathrm{H}$ dipolar interactions, and spin relaxation, extremely efficient during the water suppression delays. Above $30{ }^{\circ} \mathrm{C}$ and despite the large molecular size of SUV particles, strong ${ }^{1} \mathrm{H}$ signals became visible at chemical shifts expected for phospholipids (Figure 5F,G). This is due to increased internal motion, linked to increased fluidity of the lipid bilayer in the liquid-crystalline phase as previously reported. ${ }^{31,63}$ In conclusion, both ${ }^{1} \mathrm{H}$ and ${ }^{31} \mathrm{P}$ NMR data were consistent and reported on the temperature effect on 
internal membrane dynamics. They point to a phase transition at a temperature around the $T_{\mathrm{m}}$ of DPPC.

3.2.3. Characterization of Thermotropic Phase Transitions by ${ }^{1} H$ NMR. Thermotropic phase transitions of liposomes and phase transition temperatures $T_{\mathrm{m}}$ depend on the lipid composition and vesicle structure. ${ }^{64,65} T_{\mathrm{m}}$ is of paramount importance for thermosensitive liposomes since it dictates conditions for cargo release. $T_{\mathrm{m}}$ is conventionally measured by differential scanning calorimetry (DSC), ${ }^{65,66}$ although other biophysical methods can also be used. ${ }^{21}$ Due to the distinct dynamics of phospholipids in gel and liquid-crystalline phases, ${ }^{1} \mathrm{H}$ NMR signal integrals report on the relative populations of these two phases, and the transition can in principle be directly monitored by NMR. Such an approach was already used, but scarcely used later, to detect phase transitions in liposomes. $^{21,22}$ To probe the phase transition in more detail, we integrated the signals for isolated $\mathrm{CH}_{2}$ and $\mathrm{CH}_{3}$ groups (Figure 5FG) at various temperatures between 15 and $70{ }^{\circ} \mathrm{C}$ (Figure 6).

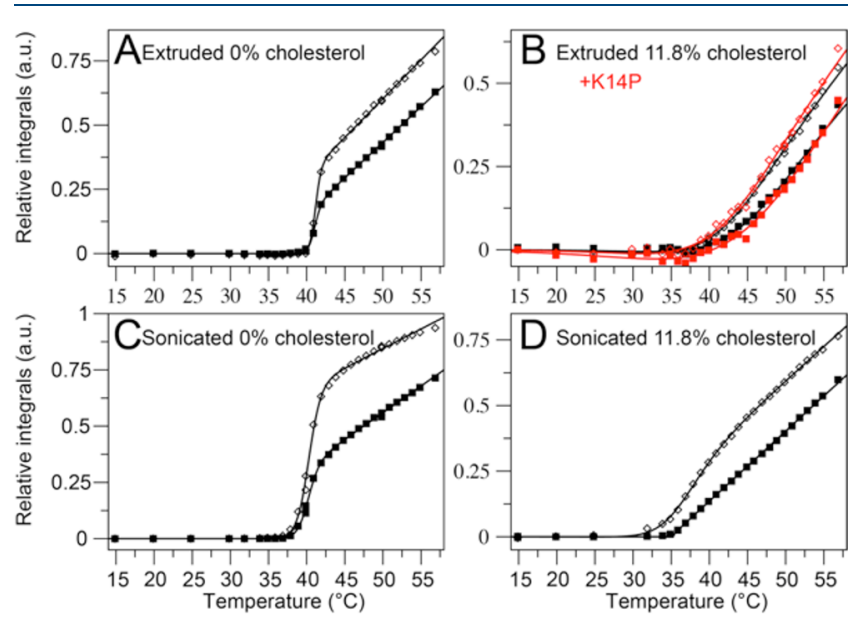

Figure 6. (A-D) Monitoring of thermotropic phase transitions in liposomes by ${ }^{1} \mathrm{H}$ NMR. The integrals of phospholipid $\mathrm{CH}_{2}$ (filled squares) and $\mathrm{CH}_{3}$ (empty diamonds) signals (Figure 5FG) were plotted versus temperature. The integral values were normalized to 1 at $70{ }^{\circ} \mathrm{C}$. For clarity, only the $15-55^{\circ} \mathrm{C}$ temperature range is shown on the figure. The panels show the data for extruded liposomes with (B) or without (A) 11.8\% cholesterol and for sonicated liposomes with (D) or without (C) $11.8 \%$ cholesterol. The temperaturedependent integrals for K14P-loaded extruded liposomes with $11.8 \%$ cholesterol are also shown in red in panel (B). The continuous lines correspond to the best fit to eq 3 over the $15-55{ }^{\circ} \mathrm{C}$ range.

For all preparations, phospholipid signals vanished below 35 ${ }^{\circ} \mathrm{C}$, in agreement with restricted motion in the gel phase. A clear change in ${ }^{1} \mathrm{H}$ NMR signal behavior, with a drastic signal increase, was visible at $\sim 40{ }^{\circ} \mathrm{C}$, which is close to the melting temperature $T_{\mathrm{m}}$ of DPPC, the main component of our liposomes (Figure 6). This confirms that ${ }^{1} \mathrm{H}$ NMR directly reports on the fluidity of the bilayer and on thermotropic phase transitions.

For cholesterol-free liposomes, a sharp transition was observed with a $T_{\mathrm{m}} \sim 40{ }^{\circ} \mathrm{C}$ (Figure 6AC). At temperatures above $T_{\mathrm{m}}$, the signal continued to increase almost linearly up to $55{ }^{\circ} \mathrm{C}$. Linear increase of signal integrals at $T>T_{\mathrm{m}}$ can be easily explained by the effect of enhanced mobility in the fluid phase with increasing temperature. At temperatures between $55^{\circ} \mathrm{C}$ and $70{ }^{\circ} \mathrm{C}$ the signal still increased, but slightly deviated from linearity (data not shown).

As previously suggested, ${ }^{21}$ we attempted to fit the NMR signal curve by a simple model based on a sigmoidal curve to model the phase transition. A pure sigmoidal curve well reproduced the behavior at low temperature and the transition but failed to explain the linear signal increase at temperatures above the transition. To take into account the linear signal increase for $T>T_{\mathrm{m}}$, this sigmoidal curve was multiplied by an ad hoc linear function (eq 3 )

$$
\text { Int }=\frac{k_{1} \times\left(T-T_{1}\right)}{1+\mathrm{e}^{k_{0} \times\left(T_{\mathrm{m}}-T\right)}}
$$

The experimental curves were very well-reproduced by this model for cholesterol-free liposomes (Figure 6A,C). The bestfit parameters, including the phase transition temperature $T_{\mathrm{m}}$ and cooperativity $k_{0}$ for the sigmoidal contribution and $T_{1}$ and $k_{1}$ parameters for the linear contribution, are given in Table 2 for cholesterol-free samples. $T_{\mathrm{m}}$ values were remarkably similar for $\mathrm{CH}_{2}$ and $\mathrm{CH}_{3}$ signals. We determined average $T_{\mathrm{m}}$ values of $41.0 \pm 0.2{ }^{\circ} \mathrm{C}$ for extruded and $40.0 \pm 0.3{ }^{\circ} \mathrm{C}$ for sonicated liposomes. This is in full agreement with the $T_{\mathrm{m}}$ of DPPC. Interestingly, the transition of sonicated liposomes seems to be slightly shifted by $\sim 1{ }^{\circ} \mathrm{C}$ toward lower temperature. Although this shift is rather weak, it may reflect the lower melting temperature of small liposomal particles induced by increased bilayer curvature, as compared to larger liposomes. ${ }^{65}$

As gel to LC phase transitions are known to be correlated with an increase in liposome size due to an increased surface area of lipids, ${ }^{67}$ we performed temperature-dependent size measurements by DLS to compare with our NMR data (Supplementary Figure 5). In the case of cholesterol-free extruded liposomes, a clear transition was observed between 40 and $45^{\circ} \mathrm{C}$ with a significant increase in particle size. In the case of sonicated liposomes, even if an overall size increase was observed, no clear gel/LC transition was visible. This analysis suggests that the DLS-derived particle size could also reveal the $\mathrm{gel} / \mathrm{LC}$ transition.

In contrast to cholesterol-free liposomes, no sharp transition was observed for cholesterol-containing liposomes (Figure $6 \mathrm{~B}, \mathrm{D})$. Instead, signals increased almost linearly with temperature above $35{ }^{\circ} \mathrm{C}$. The previously described model could nevertheless still fit the curves (Figure 6B,D). The general behavior of two apparent linear regimes below and above 40 ${ }^{\circ} \mathrm{C}$ could be nicely reproduced from eq 2 when using a ten-fold

Table 2. Best-Fit Parameters for the Thermotropic Phase Transition in Cholesterol-Free Liposomes Obtained by Fitting ${ }^{1} \mathrm{H}$ NMR Signal Intensities to Equation 3

\begin{tabular}{rlcccc}
\hline & & $T_{\mathrm{m}}\left({ }^{\circ} \mathrm{C}\right)$ & $k_{0}\left({ }^{\circ} \mathrm{C}^{-1}\right)$ & $T_{1}\left({ }^{\circ} \mathrm{C}\right)$ & $k_{1}$ \\
extruded liposomes, 0\% cholesterol & $\mathrm{CH}_{2}$ & $41.0 \pm 0.1$ & $2.6 \pm 0.8$ & $34.3 \pm 0.4$ & $0.03 \pm 0.01$ \\
& $\mathrm{CH}_{3}$ & $41.1 \pm 0.1$ & $2.7 \pm 0.3$ & $30.1 \pm 0.5$ & $0.03 \pm 0.01$ \\
sonicated liposomes, 0\% cholesterol & $\mathrm{CH}_{2}$ & $39.8 \pm 0.1$ & $1.2 \pm 0.1$ & $17.6 \pm 1.1$ & $0.02 \pm 1.1$ \\
& $\mathrm{CH}_{3}$ & $40.1 \pm 0.1$ & $1.4 \pm 0.2$ & $26.5 \pm 0.7$ & $0.02 \pm 0.01$
\end{tabular}



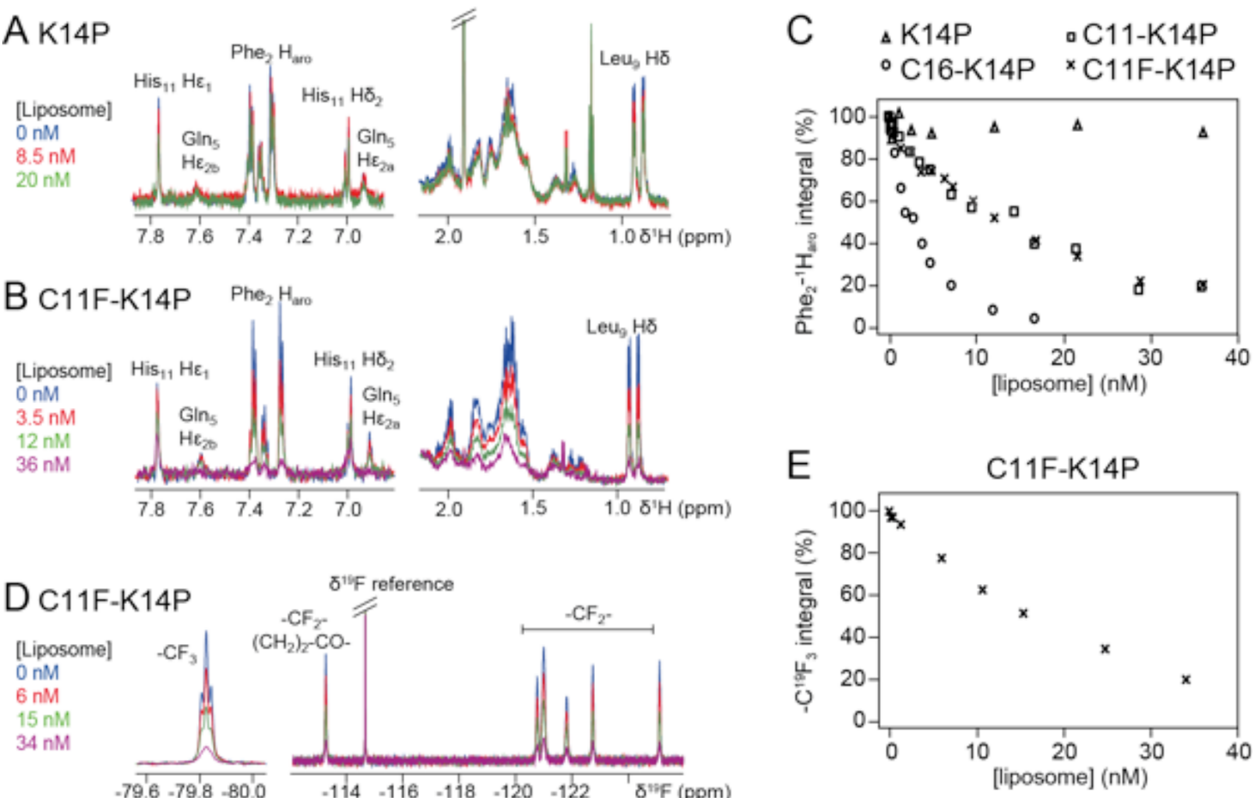

Figure 7. ${ }^{1} \mathrm{H}$ and ${ }^{19} \mathrm{~F}$ NMR titration experiments of K14 and fatty acylated K14P by extruded liposomes. Samples were in $80 \mathrm{mM}$ HEPES pH 7.4 and $100 \mathrm{mM} \mathrm{NaCl}$ buffer. Peptide concentration was kept constant at $90 \mu \mathrm{M}$. Small volumes of concentrated extruded DPPC/DMPG/cholesterol liposomes were added in a stepwise manner up to maximally $4.3 \mathrm{mg} / \mathrm{mL}(36 \mathrm{nM})$. Data were collected at $25{ }^{\circ} \mathrm{C}$, at $700 \mathrm{MHz}$ for ${ }^{1} \mathrm{H}$ and $565 \mathrm{MHz}$ for ${ }^{19} \mathrm{~F}$. (A,B) Two selected regions of ${ }^{1} \mathrm{H}$ NMR spectra of K14P and C11F-K14P, titrated by liposomes. (C) Integrals of the aromatic ${ }^{1} \mathrm{H}$ signals of $\mathrm{Phe}_{2}$ signals $(7.2-7.4 \mathrm{ppm})$ plotted as a function of liposome concentration for K14P and its three acylated variants. (D) ${ }^{19} \mathrm{~F}$ NMR spectra of C11F-K14P titrated by liposomes. The reference is 3-fluoro-4-methylbenzamidine at $-114.7 \mathrm{ppm}$. (E) Plot of the integral of the $\mathrm{CF}_{3}$ signal of C11F-K14P versus liposome concentration.

larger cooperativity factor $k_{0}\left(\sim 20{ }^{\circ} \mathrm{C}^{-1}\right)$ than that measured $\left(\sim 2{ }^{\circ} \mathrm{C}^{-1}\right)$ for cholesterol-free liposomes. However, a reliable $T_{\mathrm{m}}$ could not be retrieved. The absence of a clear transition for cholesterol-containing samples therefore probably reflects poor transition cooperativity and hence confirms the well-known effect of cholesterol on phospholipid bilayer dynamics: cholesterol increases the fluidity of membrane bilayers in the gel phase and decreases fluidity in the LC phase. The temperature $\left(\sim 35{ }^{\circ} \mathrm{C}\right)$ at which ${ }^{1} \mathrm{H}$ NMR signals start to appear for cholesterol-containing liposomes reminds of the pretransition temperature reported for cholesterol-containing liposomes. $^{68}$ Size measurements by DLS also pointed to less cooperativity in the presence of cholesterol and a pretransition starting between 30 and $35{ }^{\circ} \mathrm{C}$ (Supplementary Figure 5).

Taken together, this analysis shows that ${ }^{1} \mathrm{H}$ NMR can be used to detect at which temperature the lipid bilayer in small liposomes starts to become fluid and to qualitatively assess the cooperativity of the gel/LC phase transition. In case of high cooperativity, a reliable melting temperature can be directly and robustly estimated from very sensitive and rapidly obtained $(\sim 1$ min per spectrum $){ }^{1} \mathrm{H}$ spectra upon temperature scanning, thus offering an appealing alternative to DSC.

3.3. NMR to Characterize Interactions between Peptides and Liposomes. 3.3.1. ${ }^{1} \mathrm{H} N M R$ to Probe Partitioning of N $\alpha$-Acylated K14P into Liposomal Bilayers. Drug-liposome interactions are likely to modulate the liposome structure as well as the encapsulation efficiency, potentially impacting drug delivery properties. Here, we used ${ }^{1} \mathrm{H},{ }^{19} \mathrm{~F}$, and ${ }^{31} \mathrm{P}$ NMR to characterize peptide-liposome interactions and studied the impact of $\mathrm{N} \alpha$ acylation of the peptides with respect to partitioning into liposome bilayers.

In order to probe the relative tendency of K14P peptide variants to interact with liposomes, we titrated peptide solutions with increasing amounts of extruded cholesterol- containing liposomes and collected $1 \mathrm{D}{ }^{1} \mathrm{H}$ NMR spectra at each increment (Figure 7A,B and Supplementary Figure 6). ${ }^{1} \mathrm{H}$ NMR signals of freely tumbling peptides are sharp and intense. In contrast, severe line broadening and intensity loss are expected for liposome-bound peptides due to the slow tumbling of liposomes.

At identical liposome and peptide concentrations, larger intensity attenuation for peptide signals can thus be interpreted as higher peptide/liposome affinity, thereby allowing peptide ranking regarding their affinity for liposomes. Peptide concentration was the same for all samples $(90 \mu \mathrm{M})$ and was chosen below the CMC to ensure that peptide NMR signals were not affected by self-association. The signals of all aromatic $\mathrm{Phe}_{2}$ protons (7.2-7.4 $\mathrm{ppm}$ range) were integrated at each titration point (Figure $7 \mathrm{C}$ ).

The four different peptides displayed different behaviors during liposome titration (Supplementary Figure 6). In the case of $\mathrm{K} 14 \mathrm{P},{ }^{1} \mathrm{H}$ NMR spectra were only slightly affected with an $\sim 5-10 \%$ decrease in peak integrals (Figure $7 \mathrm{~A}, \mathrm{C}$ ). In contrast, a strong intensity decrease was observed for the three fatty-acylated peptides, when the liposome concentration was increased (Figure 7B,C and Supplementary Figure 6). No significant chemical shift variation or signal broadening was observed. This is consistent with a slow exchange mechanism at the ${ }^{1} \mathrm{H}$ chemical shift timescale $(\sim \mathrm{ms})$ between free and bound peptide states as usually observed for strong interactions. All ${ }^{1} \mathrm{H}$ NMR signals of $\mathrm{K} 14 \mathrm{P}$ variants displayed intensity decreases, suggesting that all parts of the molecules, lipid as well as peptide moieties, were involved in the interaction due to partitioning of the fatty-acylated peptides into the lipid bilayers.

Signals vanished for C16-K14P at a liposome concentration above $2.0 \mathrm{mg} / \mathrm{mL}(17 \mathrm{nM}$ ) (Figure $7 \mathrm{C}$ ), suggesting complete partitioning of the C16-K14P peptide into the lipid bilayers or 
strong binding to the surface of the liposomes. Using the relative peptide/liposome molar concentration at which all peptide molecules were bound, we estimated the maximal number of peptides bound to a single liposome particle to be $\sim 5000$ under the current experimental conditions. We estimated that the total number of phospholipids per extruded liposome was 145,000 (see Materials and Methods) and that of cholesterol was 36,000 . At saturation, $\mathrm{C} 16-\mathrm{K} 14 \mathrm{P}$ is thus present at a $2.5-3.0 \%$ molar ratio in loaded liposomes. C11$\mathrm{K} 14 \mathrm{P}$ and $\mathrm{C} 11 \mathrm{~F}-\mathrm{K} 14 \mathrm{P}$ still displayed $20 \%$ residual signal intensity at $4.3 \mathrm{mg} / \mathrm{mL}$ liposome concentration (Figure $7 \mathrm{C}$ ), indicating that only $80 \%$ partitioned into the lipid bilayers at this concentration. On the basis of these results, the four peptides were easily ranked with respect to their interaction with liposomes: C16-K14P > C11-K14P $\approx \mathrm{C} 11 \mathrm{~F}-\mathrm{K} 14 \mathrm{P} \gg$ K14P. Unsurprisingly, the fatty acyl chains appear to be the main driving force for peptide-liposome interaction in this series. Although fluorination is usually reported to increase hydrophobicity, it did not significantly modify the affinity of C11-K14P, but the longer C16 chain favored partitioning into the hydrophobic membrane environment compared to $\mathrm{C} 11$ chains.

Such an experimental setup can be used to optimize peptide/liposome formulations, when the cargo-liposome encapsulation efficiency is dominated by the interaction between the cargo with the membranes. Indeed, we show here that at $2.0 \mathrm{mg} / \mathrm{mL}^{-1}$ liposome and $90 \mu \mathrm{M} \mathrm{C16-K14P}$ peptide concentrations, the whole peptide pool is in direct contact with liposomes. At higher peptide/liposome ratios, liposomes are saturated with peptides, and a fraction of peptides is free. NMR interaction experiments can therefore give an indication about how to simultaneously maximize the encapsulation efficiency and liposome load when preparing peptide-loaded liposomes.

3.3.2. ${ }^{19} \mathrm{~F} N M R$ to Probe Fluorinated Acyl Chain Partitioning of C11F-K14P into Liposomal Bilayers. ${ }^{19} \mathrm{~F}$ is a highly sensitive nucleus for NMR, with a $1 / 2$ spin, a high gyromagnetic ratio $\left(83 \%\right.$ that of $\left.{ }^{1} \mathrm{H}\right)$, and a large spectral width. Moreover, it is $100 \%$ naturally abundant. It has recently emerged as an attractive alternative to ${ }^{1} \mathrm{H}$ NMR to probe molecular structures, dynamics, and interactions, in particular for pharmaceutical applications. ${ }^{31,47,69-72}$ In addition, ${ }^{19} \mathrm{~F}$ NMR spectra are usually not contaminated by strong solvent or buffer signals and are hence usually much simpler to analyze than ${ }^{1} \mathrm{H}$ spectra, all the more since only fluorinated molecules or positions are detectable.

We obtained high-resolution ${ }^{19} \mathrm{~F}$ NMR spectra for C11FK14P: six ${ }^{19} \mathrm{~F}$ methylene signals could be distinguished, in addition to the methyl group (Figure 7D). This stands in contrast to the $\mathrm{CH}_{2}$ region in the ${ }^{1} \mathrm{H}$ spectra that display much more overlap (Figure 2A). Of note, the ${ }^{19} \mathrm{~F}$ NMR spectrum of C11F-K14P also displayed a TFA signal at $-74.5 \mathrm{ppm}$ (Supplementary Figure 7). TFA has been almost completely removed by treatment on an ion exchange column with $<0.1 \%$ remaining, confirming ${ }^{19} \mathrm{~F}$ NMR as a convenient and sensitive tool for quality control of peptide purification.

Titration of C11F-K14P by liposomes led to an intensity and signal integral decrease for all $\mathrm{CF}_{3}$ and $\mathrm{CF}_{2}$ signals, but no ${ }^{19} \mathrm{~F}$ chemical shift variation and no signal broadening were observed (Figure 7D). As a representative example, the evolution of $\mathrm{CF}_{3}$ signal integration with increasing liposome concentration is shown in Figure 7E. This behavior is similar to that of the ${ }^{1} \mathrm{H}$ NMR signals during the same titration by liposomes (Figure 7C). It indicates a slow chemical exchange at the ${ }^{19} \mathrm{~F}$ chemical shift timescale between free C11F-K14P and C11F-K14P bound to liposomes, by insertion of $\mathrm{C} 11 \mathrm{~F}$ onto or into the lipid bilayers. The similarity of the NMR signal behavior for the peptide ( $\mathrm{Phe}_{2}$ and $\mathrm{Leu}_{9}{ }^{1} \mathrm{H}$ signals in Figure $7 \mathrm{C}$ ) and fatty acyl moieties $\left({ }^{19} \mathrm{~F}\right.$ and ${ }^{1} \mathrm{H}$ signals in Figure $7 \mathrm{E}$ and Supplementary Figure 7 ) of all three K14P variants points to decreased dynamics of the peptide moiety, once the fatty acyl chain is inserted into the liposomal bilayer.

${ }^{19} \mathrm{~F}$ NMR therefore is an ideal complement for ${ }^{1} \mathrm{H}$ NMR to rapidly and efficiently estimate partitioning into liposomal membranes. Such information is of great help to predict drug encapsulation efficiencies.

3.4. Characterization of Peptide-Loaded Liposomes and Their Load by NMR. With the aim to characterize peptide-loaded liposomes by NMR, we prepared DPPCDMPG-cholesterol liposomes loaded with K14P or with C16-K14P, by sonication and by extrusion. For C16-K14P, the encapsulation efficiency was $100 \%$ with both preparation methods. In the case of nonacylated K14P, the efficiency was $30 \pm 2$ and $50 \pm 2 \%$ for sonicated and extruded liposomes, respectively. This analysis demonstrates the efficiency of $\mathrm{C} 16$ acylation to maximize encapsulation efficiency for K14P. Notably, the encapsulation efficiency of K14P was higher in extruded liposomes, likely due to the larger size of extruded liposomes. To prepare loaded liposomes, we used peptide/ (lipid+cholesterol) ratios of less than $90 \mu \mathrm{M}: 2.0 \mathrm{mg} \mathrm{mL}^{-1}$, i.e., the ratio at which $\mathrm{C} 16-\mathrm{K} 14 \mathrm{P}$ fully partitioned into the liposome bilayer. This suggests that optimal encapsulation is obtained thanks to complete insertion of C16P-K14P into bilayers even before SUV formation. With the same peptide/ liposome ratio, K14P barely interacts with liposomes, leading to lower encapsulation efficiency as expected from solely physical entrapping.

3.4.1. Impact of the Encapsulated Peptide on Liposome Phases. We next evaluated if liposome structure and dynamics were perturbed by their load. We used again ${ }^{31} \mathrm{P}$ NMR to probe perturbations of the phospholipid head groups. Encapsulation with K14P into extruded liposomes did not lead to any significant change in the ${ }^{31} \mathrm{P}$ NMR spectra in the investigated temperature range, $5-40{ }^{\circ} \mathrm{C}$ (Figure $5 \mathrm{C}$ ). This was further corroborated by ${ }^{1} \mathrm{H}$ NMR (Figure $5 \mathrm{~F}$ ) that revealed that peptide loading had a limited impact on lipid dynamics and phase transition. This is in general agreement with the limited interaction between K14P and liposomes in saline buffer, as demonstrated above. Interestingly, extruded C16-K14P-loaded liposomes also displayed similar ${ }^{31} \mathrm{P}$ NMR spectra compared to empty liposomes (Figure 5D) and similar temperature-dependent transition (Supplementary Figure 9), indicating that fatty acyl chain insertion into the lipid bilayers did not induce significant changes in membrane dynamics. This may be ascribed to the low molar ratio of peptides in our loaded liposomes (see paragraph 3.3.1). Cryo-EM images of extruded K14P- or C16-K14P-loaded liposomes did not show further any significant difference in shape or size distribution (Supplementary Figure 4). In contrast, when the liposomes were prepared by sonication, the isotropic component of the ${ }^{31} \mathrm{P}$ spectrum nearly completely vanished (Figure 5E), suggesting that C16-K14P-loaded sonicated liposomes had membrane and particle dynamics similar to those of extruded liposomes, empty or loaded.

3.4.2. Discrimination of the ${ }^{1} H$ NMR Signals of Bulk and Encapsulated K14P. We next investigated if NMR could 
distinguish $\mathrm{K} 14 \mathrm{P}$ peptides inside and outside liposomes in peptide/liposome formulation. The spectrum of K14P-loaded liposomes displayed strong and intense signals that were assigned to the K14P peptide on the basis of chemical shifts. This demonstrates that a large peptide fraction retains high mobility, in full agreement with the weak K14P-liposome interaction identified by liposome titration experiments. Nevertheless, these K14P signals were broader than those of free peptides, in line with the restricted mobility inside the liposomes but also with transient peptide-liposome interactions. As line broadening is not sufficient to discriminate between peptide inside and outside liposomes, we needed to further demonstrate the topological localization of K14P. We noticed that in addition to line broadening, all K14P signals in K14P-loaded liposomes underwent an upfield chemical shift variation (0.05-0.1 ppm), as compared to free bulk K14P (Figure $8 \mathrm{~A}$ ) or to K14P titrated by liposomes (Figures 7 and
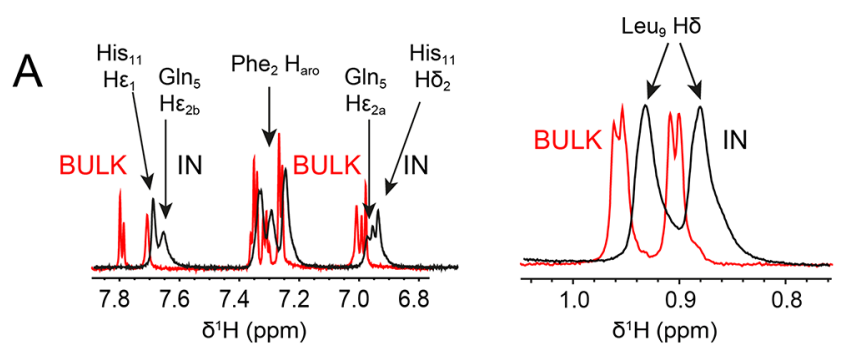

B
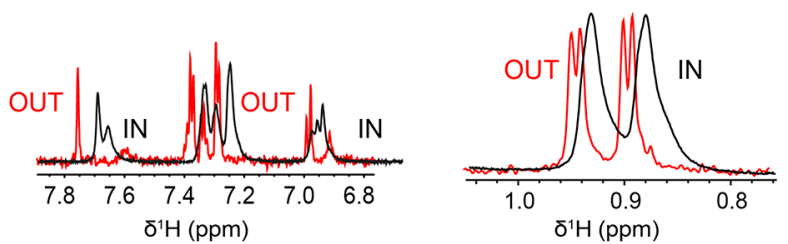

C
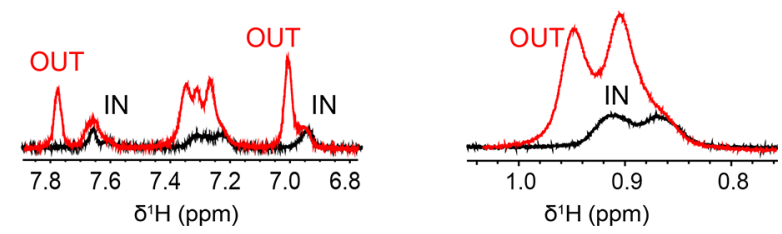

Figure 8. Discrimination of encapsulated and bulk K14P peptides by ${ }^{1} \mathrm{H}$ NMR. Only the spectral regions around the aromatic and $\mathrm{NH}_{2}$ side chain $\left(\mathrm{Phe}_{2}, \mathrm{Gln}_{5}\right.$, and $\left.\mathrm{His}_{11}\right)$ and methyl $\left(\mathrm{Leu}_{9}\right) \mathrm{K} 14 \mathrm{P}$ signals are shown. (A) $1 \mathrm{D}^{1} \mathrm{H}$ NMR spectra of a solution of free $\mathrm{K} 14 \mathrm{P}(500 \mu \mathrm{M}$, $700 \mathrm{MHz}$, and in red) versus $\mathrm{K} 14 \mathrm{P}$ encapsulated in extruded liposomes $\left(320 \mu \mathrm{M}, 60 \mathrm{mg} \mathrm{mL}^{-1}, 800 \mathrm{MHz}\right.$, and in black). (B) 1D ${ }^{1} \mathrm{H}$ NMR spectra of encapsulated K14P in extruded liposomes (320 $\mu \mathrm{M}, 60 \mathrm{mg} \mathrm{mL}{ }^{-1}, 800 \mathrm{MHz}$, and in black) versus $\mathrm{K} 14 \mathrm{P}$ outside extruded liposomes (90 $\mu \mathrm{M}, 7.2 \mathrm{mg} \mathrm{mL}^{-1}, 700 \mathrm{MHz}$, and in red). (C) $1 \mathrm{D}{ }^{1} \mathrm{H}$ NMR spectra of K14P encapsulated in sonicated liposomes before $(150 \mu \mathrm{M}$, in black) and after addition of $600 \mu \mathrm{M}$ external $\mathrm{K} 14 \mathrm{P}$ (red). All spectra were measured in $80 \mathrm{mM}$ HEPES $\mathrm{pH} 7.4$ and $100 \mathrm{mM} \mathrm{NaCl}$ buffer at $5{ }^{\circ} \mathrm{C}$.

$8 B)$. Furthermore, the general upfield shift was not limited to the peptide since other compounds such as HEPES buffer gave two sets of resonances (Supplementary Figure 8). The first set was intense and superimposed with the bulk HEPES signal, whereas the second set was weaker and shifted upfield. This suggests that the second set of HEPES signals also corresponded to an encapsulated compound. Their relative weaker intensity compared to the main peaks could be related to the total internal liposome volume in the sample. Although small differences in $\mathrm{pH}$ or buffer conditions on both sides of the liposomal membrane might affect chemical shift, this cannot explain a general shift. Generally, ${ }^{1} \mathrm{H}$ NMR chemical shifts are modulated by various parameters such as molecular reorientation, local structure, and internal dynamics, but they also depend on sample geometry, through a phenomenon called bulk magnetic susceptibility (BMS). ${ }^{73,74}$ A liposome solution can be roughly represented as (near-) spherical particles in solution placed in an NMR tube of cylindrical symmetry. This induces a difference in magnetic susceptibility that translates into an upfield shift for solutes inside spherical particles versus bulk. ${ }^{74}$ We therefore concluded that the upfield and downfield resonances corresponded to compounds localized inside (IN) and outside (OUT or bulk) liposomes.

The difference in chemical shifts inside and outside liposomes was confirmed by two additional experiments. First, a concentrated K14P peptide solution was added to an initially K14P-loaded formulation (Figure 8C), and a new set of strong downfield signals appeared downfield of the signals of encapsulated K14P in line with K14P outside liposomes. The total integral of the $\mathrm{Leu}_{9}$ signals in the $0.8-1 \mathrm{ppm}$ region was multiplied by 3.3 in reasonable agreement with the increase in total peptide concentration from 150 to $750 \mu \mathrm{M}(\times 5)$. This also suggests that the majority of $\mathrm{K} 14 \mathrm{P}$ was visible in the initial sample. Second, the encapsulated solution was heated for $70 \mathrm{~h}$ at $35{ }^{\circ} \mathrm{C}$, and a new set of similar downfield signals became visible at the expense of the initial signals, which decreased in intensity (Figure 9A). We interpreted this phenomenon as the partial release of peptides initially encapsulated into liposomes and now free to diffuse in the bulk solution. Finally, the sample also contains loaded trimethylsilylpropanesulfonate (DSS) commonly used as a reference for ${ }^{1} \mathrm{H}$ chemical shifts. The initial $1 \mathrm{D}{ }^{1} \mathrm{H}$ spectrum showed a broad signal for the DSS trimethylsilyl group at $-0.03 \mathrm{ppm}$. Heating at $35^{\circ} \mathrm{C}$ led to a new narrow downfield signal at $0 \mathrm{ppm}$ after $70 \mathrm{~h}$ (Figure 9B). This confirms the upfield shift for all encapsulated compounds, including for DSS, and further demonstrates that NMR chemical shifts can be used to probe the topological localization of compounds in liposome suspensions.

3.4.3. Translational Diffusion of Encapsulated versus Bulk by Diffusion-Ordered Spectroscopy. In order to firmly establish the topological localization of the two sets of signals, we applied NMR-based diffusion-ordered spectroscopy (DOSY), used to measure translational diffusion coefficients (D) of molecules. These coefficients depend on the hydrodynamic properties and on solvent viscosity according to the Stokes-Einstein equation. Small $\mathrm{nm}$-sized solutes, which are free to move in solution, are characterized by rapid diffusion $\left(D=10^{-9}-10^{-10} \mathrm{~m}^{2} \mathrm{~s}^{-1}\right)$, whereas larger $100 \mathrm{~nm}$-sized liposomal vesicles diffuse slowly $\left(D=10^{-11}-10^{-12} \mathrm{~m}^{2}\right.$ $\left.\mathrm{s}^{-1}\right) .^{24,75}$ Solute molecules entrapped in small vesicles are generally expected to adopt the diffusion properties of the vesicles (Figure 10A). In the DOSY NMR experiment, diffusion is revealed by applying magnetic field gradients. Signal intensity attenuation is measured for increasing gradient strengths. The extent of intensity attenuation is larger for small rapidly diffusing molecules and low for large slowly diffusing molecules. The translational diffusion coefficient $D$ can be directly extracted by fitting with an appropriate model (see Materials and Methods). DOSY has become a routine method to characterize complex samples including heterogeneous media with restricted diffusion due to confinement in small 
A

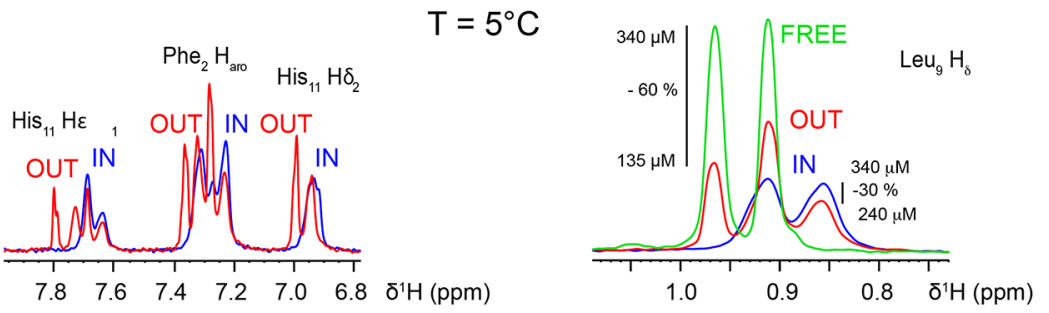

B
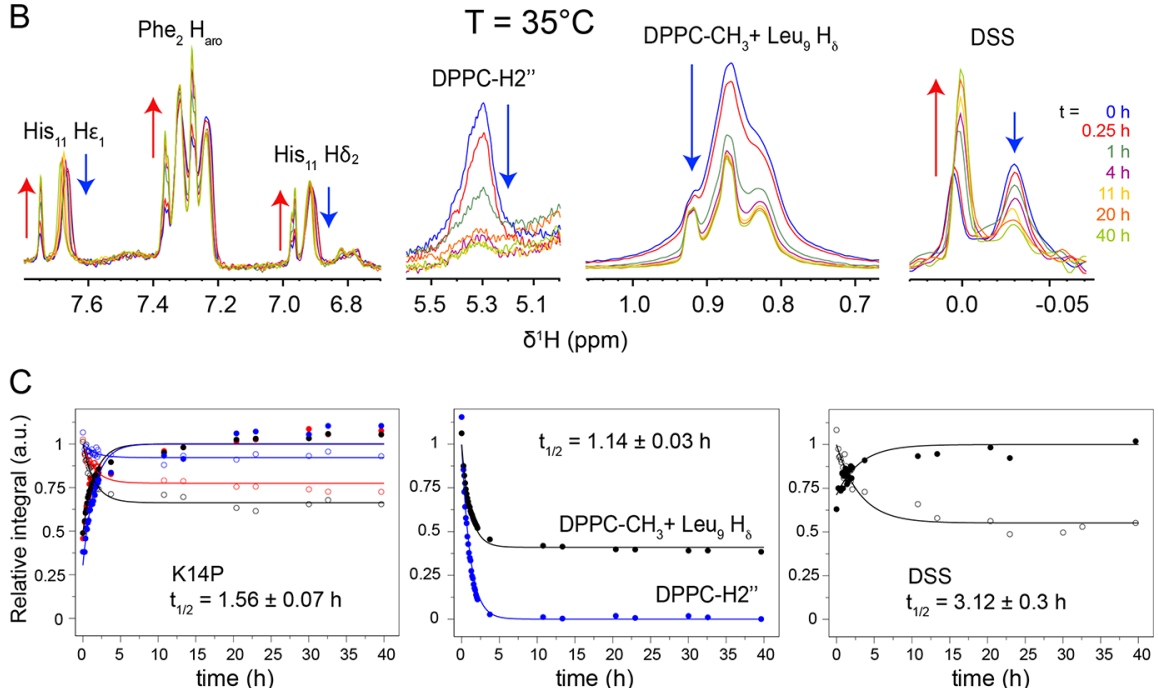

Figure 9. Release kinetics of $\mathrm{K} 14 \mathrm{P}$ encapsulated into cholesterol-containing sonicated liposomes. (A) $1 \mathrm{D}{ }^{1} \mathrm{H}$ spectra collected at $5{ }^{\circ} \mathrm{C}$ before (blue) and after (red) the heating period at $35{ }^{\circ} \mathrm{C}$ (see panel B). Only aromatic, $\mathrm{Gln}^{\mathrm{NH}} \mathrm{N}_{2}$ side chain, and methyl signals of $\mathrm{K} 14 \mathrm{P}$ are shown. The reduction of encapsulated K14P peptide concentration was estimated to be $30 \%$ from Leu $\mathrm{L}_{9} \mathrm{IN}$ signal loss. The released peptide was estimated to be $135 \mu \mathrm{M}$ by comparison with the $1 \mathrm{D}{ }^{1} \mathrm{H}$ spectrum of a $340 \mu \mathrm{M} \mathrm{K14P}$ liposome-free sample obtained under the same condition (green spectrum). (B) Series of $1 \mathrm{D}{ }^{1} \mathrm{H}$ spectra collected at $35{ }^{\circ} \mathrm{C}$ at different time points. The four spectral regions correspond to the aromatic K14P signals, the phospholipid glycerol signal (DPPC-H2") at $5.5 \mathrm{ppm}$, the $\mathrm{Leu}_{9} \mathrm{CH}_{3}$ signal overlapped with the phospholipid $\mathrm{CH}_{3}$ signal, and DSS $\mathrm{CH}$. (C) Variation of the integrals for selected signals over time and best-fit curves. The integrals were normalized to 1 for the maximal values. The left, middle, and right graphs show the data for the aromatic signals ( $\mathrm{His}_{11} \mathrm{H} \delta_{2}$ in red, $\mathrm{His}_{11} \mathrm{H} \varepsilon_{1}$ in blue, and $\mathrm{Phe}_{2}$ in black), the $\mathrm{DPPC}-\mathrm{H} 2$ " and $\mathrm{CH}{ }_{3}$ groups (overlapped with Leu9 methyl), and DSS $\mathrm{CH}_{3}$. Empty and filled circles correspond to IN and OUT signals. The data were fitted generally for each panel by a single time constant value $t_{1 / 2}$.

cavities. However, although the huge potential of this noninvasive technique has been discovered long ago to characterize particle sizes, encapsulation volumes, and encapsulation efficiency of liposomes, ${ }^{24-28,75}$ it is still rarely used for liposomal characterization and to the best of our knowledge has never been applied to liposome/peptide systems.

Using this approach, we measured, at $5{ }^{\circ} \mathrm{C}$, diffusion coefficients for encapsulated K14P peptides $(D=4.7 \pm 2.1$ $\left.10^{-12} \mathrm{~m}^{2} \mathrm{~s}^{-1}\right)$ in a freshly prepared K14P-loaded liposome sample (Figure 9A, blue spectrum, and Figure 10B). We also measured diffusion coefficients for encapsulated $(D=5.4 \pm 1.0$ $\left.10^{-12} \mathrm{~m}^{2} \mathrm{~s}^{-1}\right)$ and bulk $\left(D=3.1 \pm 0.0310^{-10} \mathrm{~m}^{2} \mathrm{~s}^{-1}\right)$ HEPES molecules (Figure 10C). By comparing these values, we deduced that liposomes as well as encapsulated compounds diffused in the $\sim 5.10^{-12} \mathrm{~m}^{2} \mathrm{~s}^{-1}$ range at $5^{\circ} \mathrm{C}$. Under the same conditions, the diffusion coefficient of $\mathrm{K} 14 \mathrm{P}$ in the absence of liposomes was $2.3 \pm 0.610^{-10} \mathrm{~m}^{2} \mathrm{~s}^{-1}$, which is in the same range as that of bulk HEPES. As in the freshly prepared sample of K14P-loaded liposomes used for DOSY measurements, K14P ${ }^{1} \mathrm{H}$ NMR signals were shifted upfield (Figure 9A, blue spectrum), and this demonstrated that upfield signals were associated to slowly diffusing molecules. This also confirmed the exclusive topological localization of K14P within the inner cavity of liposomes in a freshly prepared sample. After $70 \mathrm{~h}$ heating at $35{ }^{\circ} \mathrm{C}$, a downfield signal appeared, indicative of $\mathrm{K} 14 \mathrm{P}$ leakage to the outside (see the $1 \mathrm{D}^{1} \mathrm{H}$ NMR spectrum in Figure 10B). Interestingly, the signals of outside molecules vanished at a gradient strength of $26 \mathrm{G} / \mathrm{cm}$ under the current conditions, while high spectral quality was retained for encapsulated species (Figure 10B,E). This showed the potential of a diffusion-encoded filter to selectively monitor encapsulated compounds in an otherwise highly complex spectrum.

We also estimated from DOSY measurements that the slowly diffusing HEPES species represented $6.5 \%$ of the total HEPES signal (Figure 10C), which likely reflects the fraction of encapsulated HEPES and therefore the inner liposome volume. Based on eq 1 in Math Methods, using DLS-derived liposome sizes and a total phospholipid concentration of 0.88 $\times 60 \mathrm{mg} \mathrm{mL} \mathrm{m}^{-1}$, the inner volumes of cholesterol-containing sonicated and extruded liposomes were estimated to be 5 and $12 \%$, respectively, of the total solution. Assuming the same concentration inside and outside, as expected for HEPES, and without considering spin relaxation effects, the relative NMR signal integrals of the encapsulated versus outer species should then be 5 and $12 \%$ for the two liposome preparations. The inner volume fraction measured by DOSY $(6.5 \%)$ is therefore 

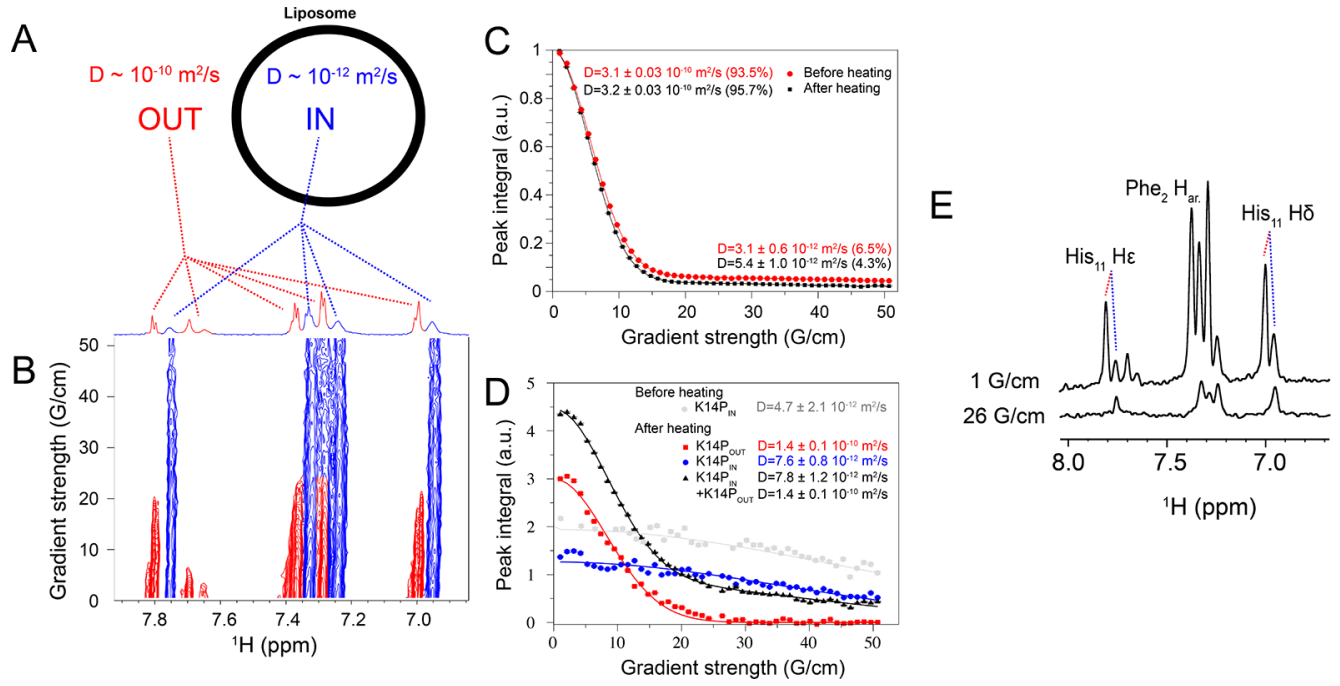

Figure 10. DOSY analysis of K14P and HEPES in K14P-loaded cholesterol-containing sonicated liposomes. (A) Molecular diffusion coefficients expected for compounds inside (IN) and outside (OUT) a liposomal particle and (B) pseudo-2D DOSY spectrum representing the evolution of $1 \mathrm{D}{ }^{1} \mathrm{H}$ traces $(x$-axis) versus the gradient strength ( $y$-axis) in DOSY experiments. Signal attenuation upon increasing magnetic field gradient strength is very efficient for compounds outside liposomes (red) and less efficient for compounds inside liposomes (blue). The DOSY data were collected on K14P-loaded liposomes at $5{ }^{\circ} \mathrm{C}$ after $70 \mathrm{~h}$ heating at $35{ }^{\circ} \mathrm{C}$. Of note, the OUT signals were absent before heating. The watersuppressed $1 \mathrm{D}{ }^{1} \mathrm{H}$ spectrum is shown on top of the pseudo-2D with IN and OUT peaks colored blue and red, respectively. An $\sim 6 \mathrm{~Hz}$ drift occurred along the ${ }^{1} \mathrm{H}$ dimension between the low and high gradient DOSY traces, possibly due to a slight $\mathrm{pH}$ change during the $16 \mathrm{~h}$ long experiment. $(\mathrm{C}, \mathrm{D})$ Signal integrals plotted versus gradient strength for different signals together with the best-fit curves based on single- or double-component Stejskal-Tanner equations. The derived diffusion coefficients are shown on the plots. Panel (C) shows the DOSY curves for HEPES signals before (black) and after (red) heating. A two-component equation was required to simultaneously fit the contribution of IN and OUT HEPES species. Panel (D) shows the DOSY data for $\mathrm{His}_{11} \mathrm{H} \delta 2$ before heating (IN in gray) or after heating (IN in blue and OUT in red). For Phe 2 aromatic protons (black), the IN/OUT signals overlapped. The whole 6.9-7.1 ppm region was integrated, and a two-component Stejskal-Tanner equation was used to retrieve diffusion coefficients. (E) $1 \mathrm{D}{ }^{1} \mathrm{H}$ traces extracted from the pseudo-2D for gradient strengths of 1 and $26 \mathrm{G} / \mathrm{cm}$ illustrating the diffusion-encoded filter effect that removes signals from rapidly diffusing compounds (OUT) while retaining high sensitivity for slowly diffusing species (IN).
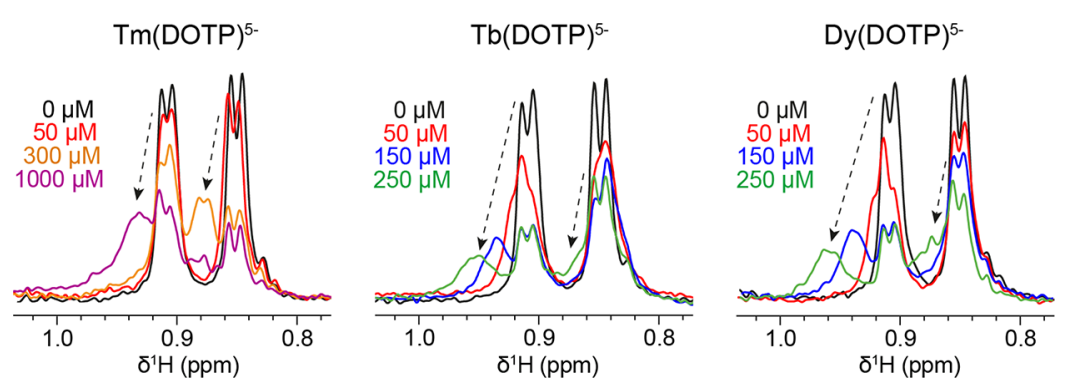

Figure 11. Effect of paramagnetic agents on K14P Leu ${ }_{9}^{1} \mathrm{H}$ NMR signals. Lanthanide(III) DOTP complexes were titrated into a solution of liposome-free $\mathrm{K} 14 \mathrm{P}$ in a $5 \mathrm{~mm}$ NMR tube. A $3 \mathrm{~mm}$ capillary containing a reference solution of K14P was placed inside the $5 \mathrm{~mm}$ tube. The NMR signal is the sum of the titrated solution and the reference signal. Spectra were acquired at a temperature of $5{ }^{\circ} \mathrm{C}$ and at $700 \mathrm{MHz}{ }^{1} \mathrm{H}$ resonance frequency. The concentration of $\mathrm{K} 14 \mathrm{P}$ was $43 \mu \mathrm{M}$ in $80 \mathrm{mM}$ HEPES pH 7.4 and $100 \mathrm{mM} \mathrm{NaCl}$. Arrows indicate the chemical shift variation and signal attenuation for each doublet due to the paramagnetic agents.

in reasonable agreement with the predicted value for sonicated liposomes.

3.4.4. Paramagnetic NMR as a Tool to Probe Topological Localization. In case of a signal overlap, addition of paramagnetic agents such as $\operatorname{Tm}(\mathrm{DOTP})^{5-}$ to a liposomal solution has been proposed with the aim of selectively shifting NMR signals of encapsulated versus nonencapsulated compounds by exploiting the lanthanide ( $\mathrm{Ln}$ )-induced pseudocontact shift (PCS) on solutes in spatial contact with the agent. $^{29}$ We tested the ability of $\operatorname{Ln}(\text { DOTP })^{5-}$ complexes with $\mathrm{Tm}^{3+}, \mathrm{Tb}^{3+}$, and $\mathrm{Dy}^{3+}$ to selectively induce PCSs on $\mathrm{K} 14 \mathrm{P}$ in the bulk solution. At $\operatorname{Ln}(\mathrm{DOTP})^{5-}$ concentrations (150-1000 $\mu \mathrm{M})$ for which a significant PCS effect became visible for $\mathrm{K} 14 \mathrm{P}$, severe line broadening also occurred (Figure 11), most likely due to a paramagnetic relaxation effect, thus reducing the sensitivity and the applicability of the method. These lanthanide complexes are negatively charged, which might favor long-living interaction with the positively charged K14P, contributing to the detrimental paramagnetic broadening effects. Furthermore, we also noted that signals of compounds both inside and outside liposomes were affected upon agent addition, which could be due to paramagnetic BMS effects ${ }^{73}$ or membrane crossing of the agent, thus limiting the applicability of the method in our case.

3.5. Impact of Thermal Treatment on Peptide Release. One major interest of liposomes is the sustained release of their cargo. Here, in order to probe the thermosensitivity of the DPPC/DMPG/cholesterol lipo- 
somes, ${ }^{76,77}$ we explored temperature-induced K14P cargo release. The ${ }^{1} \mathrm{H}$ NMR signal of $\mathrm{K} 14 \mathrm{P}$ encapsulated in sonicated liposomes remained unchanged when incubated for one week at $25{ }^{\circ} \mathrm{C}$, indicating the absence of significant peptide release at a temperature well below the $T_{\mathrm{m}}$. However, as already pointed out, changes in ${ }^{1} \mathrm{H}$ NMR spectra were observed immediately upon heating to $35{ }^{\circ} \mathrm{C}$ with the decreasing intensity for encapsulated peptides over time and a new set of downfield signals increasing in intensity (Figures $8 \mathrm{D}$ and 9B). This temperature corresponds to the subcutaneous temperature of the human body ${ }^{78}$ and is close to the $T_{\mathrm{m}}$ of the liposomes $\left(\sim 40{ }^{\circ} \mathrm{C}\right)$. The DOSY spectra collected before and after $70 \mathrm{~h}$ thermal treatment at $35^{\circ} \mathrm{C}$ showed distinct diffusion behavior for the well-separated downfield and upfield His $11 \mathrm{H} \delta_{2}$ signals (Figure 10D), revealing diffusion coefficients of $7.6 \pm 0.8 \times$ $10^{-12}$ and $1.4 \pm 0.1 \times 10^{-10} \mathrm{~m}^{2} / \mathrm{s}$ for IN and OUT signals, respectively (Figure 10). This confirmed the modified diffusion properties for the released peptide, similar to those of free $\mathrm{K} 14 \mathrm{P}$ in the absence of liposomes. Although the spectral region of $\mathrm{Phe}_{2}$ aromatic signals was crowded, similar diffusion parameters were obtained for the IN and OUT species using a two-component equation, suggesting that DOSY analysis can be efficient even in the absence of a chemical shift difference for the inner and outer spaces (Figure 10B). Altogether, these observations confirmed that heat treatment led to peptide release and confirmed the thermosensitivity of the studied liposomal composition with transition to a fluid phase at a temperature close to the $T_{\mathrm{m}}$ of DPPC.

3.6. Quantitative Analysis of Release by ${ }^{1} \mathrm{H}$ NMR. As NMR signal intensities/integrals are proportional to concentration, concentrations of multiple compounds can be quantified in situ without the need to separate molecules before analysis. Nevertheless, line broadening also affects NMR signal intensity/integral and NMR acquisition and processing parameters, and pulse sequences should be carefully chosen to determine absolute concentrations. ${ }^{79-82}$ For these reasons, signal integrals/intensities of peaks with different linewidths cannot be directly compared without care. As a work-around, absolute concentrations can be estimated by using a reference sample of known compound concentrations.

As an example, the ${ }^{1} \mathrm{H}$ spectral changes of $\mathrm{K} 14 \mathrm{P}$ encapsulated in sonicated liposomes with $11.8 \%$ cholesterol and incubated at $35{ }^{\circ} \mathrm{C}$ for $70 \mathrm{~h}$ (Figure 9A) were further analyzed. The ${ }^{1} \mathrm{H}$ signals from encapsulated $\mathrm{K} 14 \mathrm{P}$ peptides generally decreased by $30 \pm 5 \%$, suggesting that the pool of peptides initially encapsulated into the liposome decreased by the same amount. The initial encapsulated concentration was $340 \mu \mathrm{M}$, suggesting that at least $\sim 100 \mu \mathrm{M}$ peptides leaked from the inner volume. At the same time, a strong downfield signal increased. However, the difference in linewidth precluded the direct comparison of the relative signal integrals to extract relative OUT/IN populations. As an alternative, we observed that the downfield signal was $\sim 40 \%$ as intense as the signal collected in the same buffer for $\mathrm{Leu}_{9}$ methyl in a $340 \mu \mathrm{M}$ K14P solution devoid of liposomes (Figure 9A). Since external K14P showed a limited spectral change upon liposome titrations, this allowed estimating the released peptide concentration to $0.4 \times 340=135 \mu \mathrm{M}$. Such simple analysis leads to the conclusion that most of K14P in the sample gave visible NMR signals and that $\sim 35 \pm 5 \%$ of the loaded peptide was released in solution.

1D ${ }^{1} \mathrm{H}$ spectra provide a direct and very convenient approach to quantify peptide release when solutes in different compartments have distinct chemical shifts. However, this is not general, and even in the current example, $\mathrm{Leu}_{9} \mathrm{OUT} / \mathrm{IN}$ signals partially overlap (Figure 9A), making quantitation tedious. Hence, we explored DOSY-based diffusion-based filters as an alternative, when chemical shifts are similar. Figure $10 \mathrm{D}$ shows the $1 \mathrm{D}$ trace of the DOSY experiment obtained for high gradient strength $(26 \mathrm{G} / \mathrm{cm})$ that is sufficient to remove signals from fast diffusing compounds. The $\mathrm{Leu}_{9}$ and aromatic signals in the filtered spectra are not polluted by the signals of the freely diffusing species and decreased by $45 \pm 5 \%$ after the heating period, in reasonably good agreement with the $35 \pm$ $5 \%$ estimate from $1 \mathrm{D}{ }^{1} \mathrm{H}$ spectra (see above).

3.7. Real-Time Release of the Peptide. Since 1D ${ }^{1} \mathrm{H}$ spectra can be collected within minutes, it is easy to follow the real-time release kinetics in situ in a noninvasive manner. A selection of ${ }^{1} \mathrm{H}$ NMR spectra collected during the $70 \mathrm{~h}$ time course of the $35{ }^{\circ} \mathrm{C}$ thermal treatment of $\mathrm{K} 14 \mathrm{P}$ encapsulated in sonicated liposomes is shown in Figure 9B. Spectral modifications for the aromatic region as well as for DSS, the phospholipids near $5.5 \mathrm{ppm}$ and in the $0.8-1 \mathrm{ppm}$ region that also contains the $\mathrm{Leu}_{9}$ methyl signal, were observed. In the latter region, a strong signal appeared just after a temperature change from 5 to $35^{\circ} \mathrm{C}$, overlapping with the $\mathrm{Leu}_{9}$ methyl signal. This signal together with the one that appeared at 5.5 $\mathrm{ppm}$ originates from phospholipids and is reminiscent of increased membrane fluidity at $35{ }^{\circ} \mathrm{C}$. These signals progressively decreased in intensity as a function of time during several hours, suggesting a rapid burst in membrane fluidity followed by a slow re-equilibration toward a more rigid membrane. Beyond intensity changes, we also observed progressive chemical shift variations for the IN His ${ }_{11}$ signals over time (Figure 9B). Histidine side chain signals are generally exquisitely sensitive to tiny $\mathrm{pH}$ changes around their $\mathrm{p} K_{\mathrm{a}}$ value $(\sim 6-7)$ : this spectral change might reveal a time-dependent weak $\mathrm{pH}$ equilibration within liposomes.

The first $1 \mathrm{D}{ }^{1} \mathrm{H}$ spectrum was collected about $15 \mathrm{~min}$ after the temperature jump to $35{ }^{\circ} \mathrm{C}$ and showed immediate new strong OUT signals (Figure 9B) that slowly changed in intensity over time. This reveals a two-step peptide release process starting with a rapid release during the experimental dead time followed by a slower release. From signals with increasing intensities during the second release process, it can be inferred that the amplitudes of the rapid and slow process are of the same order of magnitude (Figure 9C), suggesting that about one third up to half of the peptide is rapidly released and the other two-thirds or half is slowly released. In Figure $9 \mathrm{~B}$, we show the time fate of signal integrals for different OUT and IN species normalized to their maximal values, as well as the best-fitted exponential curves. Clearly, the sample equilibrated within $5 \mathrm{~h}$ as judged from the plateau reached for $\mathrm{K} 14 \mathrm{P}$, phospholipid, and DSS signal intensities. The rate constant values could be extracted for K14P peptide (0.64 \pm $\left.0.1 \mathrm{~h}^{-1}\right)$ and DSS $\left(0.32 \pm 0.1 \mathrm{~h}^{-1}\right)$ release and for phospholipid loss of fluidity $\left(0.88 \pm 0.1 \mathrm{~h}^{-1}\right)$. The current data therefore suggest that the different processes occur at similar timescales. This may reveal that the increased membrane dynamics upon heating could be associated with cargo release or vice-versa. As a possible mechanism, peptide release might require a dynamic membrane. Bilayer stiffening would result in stopping the release, as observed here, possibly before total peptide release occurred and full equilibrium on both sides of the liposomal membrane. Taken together, this analysis shows that $1 \mathrm{D}{ }^{1} \mathrm{H}$ NMR spectra allow the rapid and 
simultaneously extraction of kinetic parameters of cargo release and membrane dynamics and are valuable tools to derive mechanistic hypotheses, such as the two-step release mechanism and coupling of liposome structural and dynamic changes with drug release. The two-step release of the peptide was achieved in part by a rapid burst followed by a slow (0.64 $h^{-1}$ ) rate but only reached $40 \%$ release efficiency. Sixty percent of the peptide remained encapsulated under the current conditions. Based on the inner liposome volume ( $\sim 5 \%)$, we would expect $95 / 5 \%$ partitioning of the peptide in the OUT/ IN environments for a complete release. The real-time and in situ NMR data therefore indicated that a large fraction of peptides was not released by the liposome formulations used here upon heating.

We further exploited the advantage of NMR, as a multiplexed technique, to monitor the fate of small DSS molecules. Figure 9C shows the time-dependent integrals for DSS IN and OUT signals in the same experiment (Figure 9B). This demonstrates that here, DSS release occurred, as for $\mathrm{K} 14 \mathrm{P}$ peptides, as a two-step process with the slower step in the $0.3 \mathrm{~h}^{-1}$ range.

\section{CONCLUSIONS}

Peptide/liposome formulations represent drug delivery systems of significant interest for drug development. ${ }^{5}$ The quality control of liposomes is a necessary step to ensure the reproducibility and the quality of the results. Furthermore, optimizing formulations requires characterizing the molecular interactions between the cargo and liposomes that dictate encapsulation yield and release kinetics. Here, we have illustrated the versatility of liquid-state ${ }^{1} \mathrm{H},{ }^{19} \mathrm{~F}$, and ${ }^{31} \mathrm{P}$ NMR spectroscopy to characterize the structure of peptides and liposomes and their mutual interactions, in complement with more direct but low-resolution DLS and cryo-TEM structural techniques. In contrast to many other methods, NMR does not need the physical purification of the different compounds, and virtually all compounds in a sample can be monitored in parallel in situ and in real time by the appropriate NMR-visible spins. In addition, chemical modifications are not required as opposed for example to fluorophore grafting, thus avoiding unwanted effects of the modification by itself on the properties of cargos. The characterization of the cargo and liposomes at the molecular and atomic levels allowed understanding of how variations in peptide structure and liposome composition and preparation methods modulate the encapsulation efficiency and the release yield and kinetics. Although NMR is not as widely available as other techniques and suffers from limited sensitivity, the wealth of information potentially accessible makes it an attractive tool to optimize peptide/liposome formulations, with potential applications to other cargos and DDSs.

\section{ASSOCIATED CONTENT}

\section{SI Supporting Information}

The Supporting Information is available free of charge at https://pubs.acs.org/doi/10.1021/acs.molpharmaceut.1c00037.

Resonance assignments of K14P; ${ }^{1} \mathrm{H}$ NMR spectra of $\mathrm{K} 14 \mathrm{P}$ peptides under different buffer and temperature conditions; chemical shift perturbations of K14P by fatty acylation with $\mathrm{C} 11, \mathrm{C} 11 \mathrm{~F}$, and $\mathrm{C} 16$; size measurements by DLS for K14P peptides and blank liposomes; cryo-
EM images and size distribution analysis of DPPC/ DMPG/11.8\% cholesterol liposomes, prepared without or with $\mathrm{K} 14 \mathrm{P}$ peptide variants; variation of volume distribution of liposomes measured by DLS; titration of K14P, C11-K14P, C11F-K14P, and C16-K14P peptide solutions by extruded DPPC/DMPG/cholesterol liposomes followed by ${ }^{1} \mathrm{H}$ NMR; complete ${ }^{19} \mathrm{~F}$ NMR spectrum of $90 \mu \mathrm{M}$ C11F-K14P; ${ }^{1} \mathrm{H}$ NMR spectrum with water suppression of freshly extruded K14P-loaded DPPC/DMPG/11.8\% cholesterol liposomes; monitoring of thermotropic phase transitions in liposomes by ${ }^{1} \mathrm{H}$ NMR loaded or not with C16-K14P (PDF)

\section{AUTHOR INFORMATION}

\section{Corresponding Authors}

Christina Sizun - Institut de Chimie des Substances Naturelles, CNRS UPR 2301, Université Paris-Saclay, LabEx LERMIT, 91190 Gif-sur-Yvette, France;

Email: christina.sizun@cnrs.fr

Ewen Lescop - Institut de Chimie des Substances Naturelles, CNRS UPR 2301, Université Paris-Saclay, LabEx LERMIT, 91190 Gif-sur-Yvette, France; O orcid.org/0000-00022623-9365; Email: ewen.lescop@cnrs.fr

\section{Authors}

Camille Doyen - Institut de Chimie des Substances Naturelles, CNRS UPR 2301, Université Paris-Saclay, LabEx LERMIT, 91190 Gif-sur-Yvette, France; Sanofi, 94403 Vitry sur Seine, France

Eric Larquet - Laboratoire de Physique de la Matiere Condensée (LPMC), Ecole Polytechnique, CNRS, Institut Polytechnique de Paris, 91128 Palaiseau, France

Pierre-Damien Coureux - Laboratoire de Biologie Structurale de la Cellule (BIOC), CNRS, Ecole Polytechnique, Institut Polytechnique de Paris, 91128 Palaiseau, France

Oriane Frances - Sanofi, 94403 Vitry sur Seine, France

Frédéric Herman - Sanofi, 94403 Vitry sur Seine, France

Serge Sablé - Sanofi, 94403 Vitry sur Seine, France

Jean-Pierre Burnouf - Sanofi, 94403 Vitry sur Seine, France

Complete contact information is available at:

https://pubs.acs.org/10.1021/acs.molpharmaceut.1c00037

\section{Author Contributions}

C.D. performed investigation and writing of the original draft. P.-D.C. and performed investigation of cryo-TEM. O.F., F.H., and J.-P.B. performed supervision and formal analysis. O.F. helped in funding acquisition. S.S. performed project administration and funding acquisition. C.S. and performed conceptualization, investigation, methodology, supervision, writing the original draft, and funding acquisition.

\section{Funding}

C.D. had a $\mathrm{PhD}$ grant from the ANRT (CIFRE). Financial support from the IR-RMN-THC Fr3050 CNRS for conducting this research is gratefully acknowledged. This work was supported by the French Infrastructure for Integrated Structural Biology (FRISBI) ANR-10-INBS-0005.

\section{Notes}

The authors declare no competing financial interest.

\section{ACKNOWLEDGMENTS}

The authors would like to thank Vincent Guérineau for the mass spectrometry analysis of the peptide; Ronan Larget, 
Alexandre Raux, and Géraldine Manette for the peptide synthesis; Vincent Gervat for the peptide purification; MarieFrançoise Nicolas for the help with liposome preparation, JeanFrançois Gallard and François Giraud for NMR technical assistance; and Jean-Nicolas Dumez for scientific discussions on diffusion and DOSY experiments.

\section{ABBREVIATIONS}

CHOL, cholesterol; CMC, critical micellar concentration; DDS, drug delivery system; DIEA, $N, N$-diisopropylethylamine; DLS, dynamic light scattering; DMF, $N, N$-dimethylformamide; DMPG, 1,2-dimyristoyl-sn-glycero-3-phospho-(1'-rac-glycerol); DPPC, 1,2-dipalmitoyl-sn-glycero-3-phosphocholine; HPLC, high-pressure liquid chromatography; HTCU, O(1H-6-chlorobenzotriazole-1-yl)-1,1,3,3-tetramethylaminium hexafluorophosphate; LC, liquid-crystalline; LUV, large unilamellar vesicle; MLV, multilamellar vesicle; NMR, nuclear magnetic resonance; NOE, nuclear Overhauser effect; ssNMR, solid-state NMR; SUV, small unilamellar vesicle; TFA, trifluoroacetic acid; TIS, triisopropylsilane

\section{REFERENCES}

(1) Fosgerau, K.; Hoffmann, T. Peptide therapeutics: Current status and future directions. Drug Discovery Today 2015, 20, 122-128.

(2) Lau, J. L.; Dunn, M. K. Therapeutic peptides: Historical perspectives, current development trends, and future directions. Bioorg. Med. Chem. 2018, 26, 2700-2707.

(3) Tan, M. L.; Choong, P. F. M.; Dass, C. R. Recent developments in liposomes, microparticles and nanoparticles for protein and peptide drug delivery. Peptides 2010, 31, 184-193.

(4) Swaminathan, J.; Ehrhardt, C. Liposomal delivery of proteins and peptides. Expert Opin. Drug Delivery 2012, 9, 1489-1503.

(5) Du, A. W.; Stenzel, M. H. Drug carriers for the delivery of therapeutic peptides. Biomacromolecules 2014, 15, 1097-1114.

(6) Torchilin, V. P. Recent advances with liposomes as pharmaceutical carriers. Nat. Rev. Drug Discovery 2005, 4, 145-160.

(7) Allen, T. M.; Cullis, P. R. Liposomal drug delivery systems: From concept to clinical applications. Adv. Drug Delivery Rev. 2013, $65,36-48$.

(8) Crommelin, D. J. A.; van Hoogevest, P.; Storm, G. The role of liposomes in clinical nanomedicine development. What now? Now what? J. Controlled Release 2020, 318, 256-263.

(9) Edwards, K. A.; Baeumner, A. J. Analysis of liposomes. Talanta 2006, 68, 1432-1441.

(10) Gómez-Hens, A.; Fernández-Romero, J. M. Analytical methods for the control of liposomal delivery systems. TrAC, Trends Anal. Chem. 2006, 25, 167-178.

(11) Maherani, B.; Arab-Tehrany, E.; Mozafari, M. R.; Gaiani, C.; Linder, M. Liposomes: A Review of Manufacturing Techniques and Targeting Strategies. Curr. Nanosci. 2011, 7, 436-452.

(12) Salnikov, E.; Aisenbrey, C.; Vidovic, V.; Bechinger, B. Solidstate NMR approaches to measure topological equilibria and dynamics of membrane polypeptides. Biochim. Biophys. Acta, Biomembr. 2010, 1798, 258-265.

(13) Hong, M.; Su, Y. Structure and dynamics of cationic membrane peptides and proteins: Insights from solid-state NMR. Protein Sci. 2011, 20, 641-655.

(14) Fillion, M., Ouellet, M., Auger, M. (2018) Solid-State NMR Studies of the Interactions and Structure of Antimicrobial Peptides in Model Membranes. In Modern Magnetic Resonance; Springer International Publishing: Cham, pp. 617-634.

(15) Su, Y.; Waring, A. J.; Ruchala, P.; Hong, M. Membrane-Bound Dynamic Structure of an Arginine-Rich Cell-Penetrating Peptide, the Protein Transduction Domain of HIV TAT, from Solid-State NMR. Biochemistry 2010, 49, 6009-6020.

(16) Viger-Gravel, J.; Schantz, A.; Pinon, A. C.; Rossini, A. J.; Schantz, S.; Emsley, L. Structure of Lipid Nanoparticles Containing
siRNA or mRNA by Dynamic Nuclear Polarization-Enhanced NMR Spectroscopy. J. Phys. Chem. B 2018, 122, 2073-2081.

(17) Watts, A. Solid-state NMR in drug design and discovery for membrane-embedded targets. Nat. Rev. Drug Discovery 2005, 4, 555568.

(18) Io, T.; Fukami, T.; Yamamoto, K.; Suzuki, T.; Xu, J.; Tomono, K.; Ramamoorthy, A. Homogeneous Nanoparticles To Enhance the Efficiency of a Hydrophobic Drug, Antihyperlipidemic Probucol, Characterized by Solid-State NMR. Mol. Pharmaceutics 2010, 7, 299305.

(19) Skorupska, E.; Jeziorna, A.; Kazmierski, S.; Potrzebowski, M. J. Recent progress in solid-state NMR studies of drugs confined within drug delivery systems. Solid State Nucl. Magn. Reson. 2014, 57-58, 216.

(20) Phyo, P.; Zhao, X.; Templeton, A. C.; Xu, W.; Cheung, J. K.; $\mathrm{Su}, \mathrm{Y}$. Understanding Molecular Mechanism of Biologics Drug Delivery and Stability from NMR Spectroscopy. Adv. Drug Delivery Rev. 2021, DOI: 10.1016/j.addr.2021.02.007.

(21) Pentak, D. Alternative methods of determining phase transition temperatures of phospholipids that constitute liposomes on the example of DPPC and DMPC. Thermochim. Acta 2014, 584, 36-44.

(22) Pentak, D. Physicochemical properties of liposomes as potential anticancer drugs carriers. Interaction of etoposide and cytarabine with the membrane: Spectroscopic studies. Spectrochim. Acta, Part A 2014, 122, 451-460.

(23) Hathout, R. M.; Woodman, T. J. Applications of NMR in the characterization of pharmaceutical microemulsions. J. Controlled Release 2012, 161, 62-72.

(24) Hinton, D. P.; Johnson, C. S., Jr. Simultaneous measurement of vesicle diffusion coefficients and trapping efficiencies by means of diffusion ordered 2D NMR spectroscopy. Chem. Phys. Lipids 1994, $69,175-178$.

(25) Denkova, P.; Momekova, D.; Rangelov, S.; Lambov, N.; Willem, R. Investigation of sterically stabilized liposomes by diffusion ordered NMR spectroscopy. J. Controlled Release 2010, 148, e47-e48.

(26) Urushibara, T.; Hicks, R. Effect of Liposome Surface Charge and Peptide Side Chain Charge Density on Antimicrobial PeptideMembrane Binding as Determined by Circular Dichroism and Nuclear Magnetic Resonance Spectroscopy. J. Membr. Sci. Technol. 2013, 03, 124.

(27) Leal, C.; Rögnvaldsson, S.; Fossheim, S.; Nilssen, E. A.; Topgaard, D. Dynamic and structural aspects of PEGylated liposomes monitored by NMR. J. Colloid Interface Sci. 2008, 325, 485-493.

(28) Sabatino, P.; Saveyn, P.; Martins, J. C.; Van Der Meeren, P. Enclosed volume determination of concentrated dioctadecyldimethylammonium chloride (DODAC) vesicular dispersions by lowresolution proton NMR diffusometry and T 2 relaxometry. Langmuir 2011, 27, 4532-4540.

(29) Zhang, X. M.; Patel, A. B.; De Graaf, R. A.; Behar, K. L. Determination of liposomal encapsulation efficiency using proton NMR spectroscopy. Chem. Phys. Lipids 2004, 127, 113-120.

(30) Guimarães, D.; Noro, J.; Loureiro, A.; Cavaco-Paulo, A.; Nogueira, E. Quantification of drugs encapsulated in liposomes by $1 \mathrm{H}$ NMR. Colloids Surf., B 2019, 179, 414-420.

(31) Da Costa, G.; Mouret, L.; Chevance, S.; Le Rumeur, E.; Bondon, A. NMR of molecules interacting with lipids in small unilamellar vesicles. Eur. Biophys. J. 2007, 36, 933-942.

(32) Tatemoto, K.; Hosoya, M.; Habata, Y.; Fujii, R.; Kakegawa, T.; Zou, M. X.; Kawamata, Y.; Fukusumi, S.; Hinuma, S.; Kitada, C.; Kurokawa, T.; Onda, H.; Fujino, M. Isolation and characterization of a novel endogenous peptide ligand for the human APJ receptor. Biochem. Biophys. Res. Commun. 1998, 251, 471-476.

(33) El Messari, S.; Iturrioz, X.; Fassot, C.; De Mota, N.; Roesch, D.; Llorens-Cortes, C. Functional dissociation of apelin receptor signaling and endocytosis: Implications for the effects of apelin on arterial blood pressure. J. Neurochem. 2004, 90, 1290-1301.

(34) Wysocka, M. B.; Pietraszek-Gremplewicz, K.; Nowak, D. The Role of Apelin in Cardiovascular Diseases, Obesity and Cancer. Front. Physiol. 2018, 9, 557. 
(35) Serpooshan, V.; Sivanesan, S.; Huang, X.; Mahmoudi, M.; Malkovskiy, A. V.; Zhao, M.; Inayathullah, M.; Wagh, D.; Zhang, X. J.; Metzler, S.; Bernstein, D.; Wu, J. C.; Ruiz-Lozano, P.; Rajadas, J. [Pyr1]-Apelin-13 delivery via nano-liposomal encapsulation attenuates pressure overload-induced cardiac dysfunction. Biomaterials 2015, 37, 289-298.

(36) Brash, L.; Barnes, G. D.; Brewis, M. J.; Church, A. C.; Gibbs, S. J.; Howard, L. S. G. E.; Jayasekera, G.; Johnson, M. K.; McGlinchey, N.; Onorato, J.; Simpson, J.; Stirrat, C.; Thomson, S.; Watson, G.; Wilkins, M. R.; Xu, C.; Welsh, D. J.; Newby, D. E.; Peacock, A. J. Short-Term Hemodynamic Effects of Apelin in Patients With Pulmonary Arterial Hypertension. JACC Basic Transl. Sci. 2018, 3, $176-186$.

(37) Berry, M. F.; Pirolli, T. J.; Jayasankar, V.; Burdick, J.; Morine, K. J.; Gardner, T. J.; Woo, Y. J. Apelin has in vivo inotropic effects on normal and failing hearts. Circulation 2004, 110, II-187.

(38) Maguire, J. J.; Kleinz, M. J.; Pitkin, S. L.; Davenport, A. P. [Pyr1] apelin-13 identified as the predominant apelin isoform in the human heart: Vasoactive mechanisms and inotropic action in disease. Hypertension 2009, 54, 598-604.

(39) Murza, A.; Belleville, K.; Longpré, J.-M.; Sarret, P.; Marsault, É. Stability and degradation patterns of chemically modified analogs of apelin-13 in plasma and cerebrospinal fluid. Pept. Sci. 2014, 102, 297303.

(40) Jia, Z. Q.; Hou, L.; Leger, A.; Wu, I.; Kudej, A. B.; Stefano, J.; Jiang, C.; Pan, C. Q.; Akita, G. Y. Cardiovascular effects of a PEGylated apelin. Peptides 2012, 38, 181-188.

(41) Kawahara, H.; Naito, H.; Takara, K.; Wakabayashi, T.; Kidoya, H.; Takakura, N. Tumor Endothelial Cell-Specific Drug Delivery System Using Apelin-Conjugated Liposomes. PLoS One 2013, 8, No. e65499.

(42) Langelaan, D. N.; Bebbington, E. M.; Reddy, T.; Rainey, J. K. Structural insight into G-protein coupled receptor binding by apelin. Biochemistry 2009, 48, 537-548.

(43) Shin, K.; Sarker, M.; Huang, S. K.; Rainey, J. K. Apelin conformational and binding equilibria upon micelle interaction primarily depend on membrane-mimetic headgroup. Sci. Rep. 2017, $7,15433$.

(44) Jourdain de Muizon, C.; Ramanoudjame, S. M.; Esteoulle, L.; Ling, C.; Brou, G.; Anton, N.; Vandamme, T.; Delsuc, M.-A.; Bonnet, D.; Kieffer, B. Self-organization Properties of a GPCR-Binding Peptide with a Fluorinated Tail Studied by Fluorine NMR Spectroscopy. ChemBioChem 2021, 22, 657-661.

(45) Patterson, R. E.; Weatherbee-Martin, N.; Rainey, J. K. PyreneApelin Conjugation Modulates Fluorophore- and Peptide-Micelle Interactions. J. Phys. Chem. B 2017, 121, 4768-4777.

(46) Lutsiak, M. E.; Kwon, G. S.; Samuel, J. Analysis of peptide and lipopeptide content in liposomes. J. Pharm. Pharm. Sci. 2002, 5, 279284.

(47) Dalvit, C.; Vulpetti, A. Ligand-Based Fluorine NMR Screening: Principles and Applications in Drug Discovery Projects. J. Med. Chem. 2019, 2218.

(48) Vranken, W. F.; Boucher, W.; Stevens, T. J.; Fogh, R. H.; Pajon, A.; Llinas, M.; Ulrich, E. L.; Markley, J. L.; Ionides, J.; Laue, E. D. The CCPN data model for NMR spectroscopy: development of a software pipeline. Proteins 2005, 59, 687-696.

(49) Balayssac, S.; Delsuc, M. A.; Gilard, V.; Prigent, Y.; MaletMartino, M. Two-dimensional DOSY experiment with Excitation Sculpting water suppression for the analysis of natural and biological media. J. Magn. Reson. 2009, 196, 78-83.

(50) Stejskal, E. O.; Tanner, J. E. Spin diffusion measurements: Spin echoes in the presence of a time-dependent field gradient. J. Chem. Phys. 1965, 42, 288-292.

(51) Wüthrich, K. NMR of Proteins and Nucleic Acids; WileyInterscience, 1986.

(52) Shin, K.; Chapman, N. A.; Sarker, M.; Kenward, C.; Huang, S. K.; Weatherbee-Martin, N.; Pandey, A.; Dupré, D. J.; Rainey, J. K. Bioactivity of the putative apelin proprotein expands the repertoire of apelin receptor ligands. Biochim. Biophys. Acta, Gen. Subj. 2017, 1861, 1901-1912.

(53) Kjaergaard, M.; Brander, S.; Poulsen, F. M. Random coil chemical shift for intrinsically disordered proteins: effects of temperature and $\mathrm{pH}$. J. Biomol. NMR 2011, 49, 139-149.

(54) Nguyen, M. V. D.; Brik, M. E.; Ouvrard, B. N.; Courtieu, J.; Nicolas, L.; Gaudemer, A. Synthesis of new lipophilic ligands and NMR measurement of their critical micellar concentration (CMC). Bull. Soc. Chim. Belg. 2010, 105, 181-183.

(55) Helvig, S.; Azmi, I. D. M.; Moghimi, S. M.; Yaghmur, A. Recent advances in Cryo-TEM imaging of soft lipid nanoparticles. AIMS Biophys. 2015, 2, 116-130.

(56) Kuntsche, J.; Horst, J. C.; Bunjes, H. Cryogenic transmission electron microscopy (cryo-TEM) for studying the morphology of colloidal drug delivery systems. Int. J. Pharm. 2011, 417, 120-137.

(57) Almgren, M.; Edwards, K.; Karlsson, G. Cryo transmission electron microscopy of liposomes and related structures. Colloids Surf., A 2000, 174, 3-21.

(58) Baxa, U. Imaging of liposomes by transmission electron microscopy. Methods Mol. Biol. 2018, 1682, 73-88.

(59) Bhattacharjee, S. DLS and zeta potential - What they are and what they are not? J. Controlled Release 2016, 235, 337-351.

(60) Tejera-Garcia, R.; Parkkila, P.; Zamotin, V.; Kinnunen, P. K. J. Principles of rational design of thermally targeted liposomes for local drug delivery. Nanomedicine 2014, 10, 1243-1252.

(61) Filippov, A. V.; Khakimov, A. M.; Munavirov, B. V. ${ }^{31}$ P NMR studies of phospholipids. Annu. Rep. NMR Spectrosc. 2015, 85, 27-92.

(62) Schiller, J.; Muller, M.; Fuchs, B.; Arnold, K.; Huster, D. 31P NMR Spectroscopy of Phospholipids: From Micelles to Membranes. Curr. Anal. Chem. 2007, 3, 283-301.

(63) Mouret, L.; Da Costa, G.; Bondon, A. Sterols associated with small unilamellar vesicles (SUVs): intrinsic mobility role for ${ }^{1} \mathrm{H}$ NMR detection. Magn. Reson. Chem. 2014, 52, 339-344.

(64) Koynova, R.; Caffrey, M. Phases and phase transitions of the phosphatidylcholines. Biochim. Biophys. Acta 1998, 1376, 91-145.

(65) Biltonen, R. L.; Lichtenberg, D. The use of differential scanning calorimetry as a tool to characterize liposome preparations. Chem. Phys. Lipids 1993, 64, 129-142.

(66) Chiu, M.; Prenner, E. Differential scanning calorimetry: An invaluable tool for a detailed thermodynamic characterization of macromolecules and their interactions. J. Pharm. BioAllied Sci. 2011, 3, 39-59.

(67) Yager, P.; Sheridan, J. P.; Peticolas, W. L. Changes in size and shape of liposomes undergoing chain melting transitions as studied by optical microscopy. Biochim. Biophys. Acta, Biomembr. 1982, 693, 485-491.

(68) Heimburg, T. A Model for the Lipid Pretransition: Coupling of Ripple Formation with the Chain-Melting Transition. Biophys. J. 2000, 78, 1154-1165.

(69) Dolbier, W. R. Guide to Fluorine NMR for Organic Chemists; John Wiley \& Sons, 2008.

(70) Yu, J. X.; Hallac, R. R.; Chiguru, S.; Mason, R. P. New frontiers and developing applications in 19F NMR. Prog. Nucl. Magn. Reson. Spectrosc. 2013, 70, 25-49.

(71) Dalvit, C. Ligand- and substrate-based 19F NMR screening: Principles and applications to drug discovery. Prog. Nucl. Magn. Reson. Spectrosc. 2007, 51, 243-271.

(72) Kitevski-LeBlanc, J. L.; Prosser, R. S. Current applications of 19F NMR to studies of protein structure and dynamics. Prog. Nucl. Magn. Reson. Spectrosc. 2012, 62, 1-33.

(73) Chu, K. - C.; Xu, Y.; Balschi, J. A.; Springer, C. S. Bulk magnetic susceptibility shifts in $\mathrm{nmr}$ studies of compartmentalized samples: use of paramagnetic reagents. Magn. Reson. Med. 1990, 13, 239-262.

(74) Kuchel, P. W.; Chapman, B. E.; Bubb, W. A.; Hansen, P. E.; Durrant, C. J.; Hertzberg, M. P. Magnetic susceptibility: Solutions, emulsions, and cells. Concepts Magn. Reson., Part A 2003, 30, 69-74.

(75) Hinton, D. P.; Johnson, C. S., Jr. Diffusion ordered 2D NMR spectroscopy of phospholipid vesicles: Determination of vesicle size distributions. J. Phys. Chem. 1993, 97, 9064-9072. 
(76) Kneidl, B.; Peller, M.; Winter, G.; Lindner, L.; Hossann, M. Thermosensitive liposomal drug delivery systems: state of the art review. Int. J. Nanomed.. 2014, 9, 4387-4398.

(77) Weinstein, J. N.; Magin, R. L.; Yatvin, M. B.; Zaharko, D. S. Liposomes and local hyperthermia: Selective delivery of methotrexate to heated tumors. Science 1979, 204, 188-191.

(78) Bierman, W. The temperature of the skin surface. J. Am. Med. Assoc. 1936, 106, 1158-1162.

(79) Bharti, S. K.; Roy, R. Quantitative $1 \mathrm{H}$ NMR spectroscopy. TrAC, Trends Anal. Chem. 2012, 35, 5-26.

(80) Singh, S.; Roy, R. The application of absolute quantitative ${ }^{1} \mathrm{H}$ NMR spectroscopy in drug discovery and development. Expert Opin. Drug Discovery 2016, 11, 695-706.

(81) Akoka, S.; Remaud, G. S. NMR-based isotopic and isotopomic analysis. Prog. Nucl. Magn. Reson. Spectrosc. 2020, 120-121, 1-24.

(82) Crook, A. A.; Powers, R. Quantitative NMR-Based Biomedical Metabolomics: Current Status and Applications. Molecules 2020, 25, 5128. 